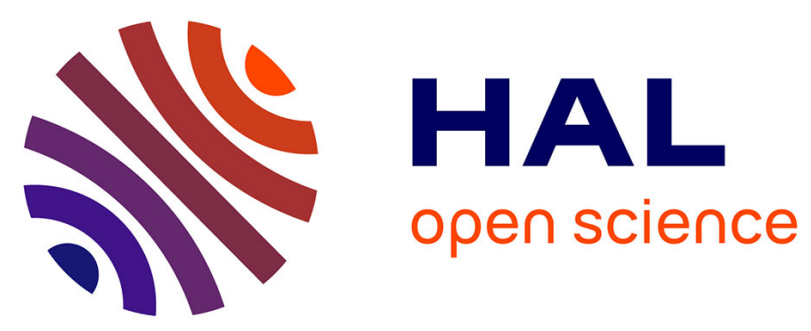

\title{
Pressure Dependent Low Temperature Kinetics for CN + CH3CN: Competition between Chemical Reaction and van der Waals Complex Formation
}

Chantal Sleiman, Sergio González, Stephen J. Klippenstein, D. Talbi, Gisèle El Dib, André Canosa

\section{To cite this version:}

Chantal Sleiman, Sergio González, Stephen J. Klippenstein, D. Talbi, Gisèle El Dib, et al.. Pressure Dependent Low Temperature Kinetics for CN + CH3CN: Competition between Chemical Reaction and van der Waals Complex Formation. Physical Chemistry Chemical Physics, 2016, PCCP, 18 (22), pp.15118-15132. 10.1039/C6CP01982J . hal-01345465

\section{HAL Id: hal-01345465 \\ https://hal.science/hal-01345465}

Submitted on 11 Oct 2016

HAL is a multi-disciplinary open access archive for the deposit and dissemination of scientific research documents, whether they are published or not. The documents may come from teaching and research institutions in France or abroad, or from public or private research centers.
L'archive ouverte pluridisciplinaire HAL, est destinée au dépôt et à la diffusion de documents scientifiques de niveau recherche, publiés ou non, émanant des établissements d'enseignement et de recherche français ou étrangers, des laboratoires publics ou privés. 


\section{Pressure Dependent Low Temperature Kinetics for $\mathrm{CN}+\mathrm{CH}_{3} \mathrm{CN}$ : Competition between Chemical Reaction and van der Waals Complex Formation}

Chantal Sleiman ${ }^{1}$, Sergio González ${ }^{2}$, Stephen J. Klippenstein ${ }^{3}$, Dahbia Talbi ${ }^{4}$, Gisèle El Dib ${ }^{1}$ and André Canosa ${ }^{1}$

${ }^{1}$ Département de Physique Moléculaire, Institut de Physique de Rennes, UMR 6251 du CNRS Université de Rennes 1, Bat. 11C, Campus de Beaulieu, 263 Avenue du Général Leclerc, 35042 Rennes Cedex, France.

${ }^{2}$ Departamento de Química Física, Facultad de Ciencias y Tecnologías Químicas, Universidad de Castilla La Mancha, Campus Universitario, 13071 Ciudad Real, Spain.

${ }^{3}$ Argonne National Laboratory, Chemical Sciences and Engineering Division, Argonne, IL 604394837, United States.

${ }^{4}$ Laboratoire Univers et Particules de Montpellier - UMR 5299 du CNRS - Université de Montpellier, Campus Triolet, Place Eugène Bataillon CC 72, 34095 Montpellier Cedex 05, France.

Corresponding author: André Canosa, andre.canosa@univ-rennes1.fr 


\begin{abstract}
The gas phase reaction between the $\mathrm{CN}$ radical and acetonitrile $\mathrm{CH}_{3} \mathrm{CN}$ was investigated experimentally, at low temperatures, with the CRESU apparatus and a slow flow reactor to explore the temperature dependence of its rate coefficient from $354 \mathrm{~K}$ down to $23 \mathrm{~K}$. Whereas a standard Arrhenius behavior was found at T > $200 \mathrm{~K}$, indicating the presence of an activation barrier, a dramatic increase in the rate coefficient by a factor of 130 was observed when the temperature was decreased from 168 to $123 \mathrm{~K}$. The reaction was found to be pressure independent at $297 \mathrm{~K}$ unlike the experiments carried out at 52 and $132 \mathrm{~K}$. The work was complemented by ab-initio transition state theory based master equation calculations using reaction pathways investigated with highly accurate thermochemical protocols. The role of collisional stabilization of a $\mathrm{CN}$.... $\mathrm{CH}_{3} \mathrm{CN}$ van der Waals complex and of tunneling induced $\mathrm{H}$ atom abstractions were also considered. The experimental pressure dependence at 52 and $132 \mathrm{~K}$ is well reproduced by the theoretical calculations provided that an anharmonic state density is considered for the van der Waals complex $\mathrm{CH}_{3} \mathrm{CN}$...CN and its Lennard-Jones radius is adjusted. Furthermore, these calculations indicate that the experimental observations correspond to the fall-off regime and that tunneling remains small in the low-pressure regime. Hence, the studied reaction is essentially an association process at very low temperature. Implications for the chemistry of interstellar clouds and Titan are discussed.
\end{abstract}




\section{Introduction}

Acetonitrile, also known as cyanomethane, ethanenitrile, or methyl cyanide $\left(\mathrm{CH}_{3} \mathrm{CN}\right)$ is a colorless liquid under standard conditions of pressure and temperature. It is commonly used as a solvent in industry and laboratory research and is an important component in the syntheses of pesticides and pharmaceutical or photographical products.

In natural gas phase environments it has been found to be ubiquitous and therefore there is a large literature describing its detection in regions of very different physical conditions. In the Earth's troposphere it has been observed as issuing mainly from biomass burning emissions. ${ }^{1}$ Its low reactivity with atmospheric constituents makes it a long-lived pollutant that can reach the lower stratosphere. ${ }^{2}$ It has also been identified in other solar system objects, especially in the stratosphere and ionosphere of Titan, Saturn's well known satellite ${ }^{3,4}$ and in several comets. ${ }^{5,6}$

Because of its symmetric top geometry and its high dipole moment (3.92 Debye), acetonitrile is particularly well suited for millimeter-wave detection of its various and closely spaced rotational transitions. Therefore, it is currently used as a thermometer to probe interstellar environments and it is a useful tracer of dense gas. ${ }^{7}$ For these reasons, many observations of its presence in extrasolar environments have been reported in the literature. In the Interstellar Medium (ISM), acetonitrile was first detected in 1971 toward the Galactic center in the molecular clouds near Sgr B2 and Sgr A. ${ }^{8}$ Later, it was observed in dark clouds such as TMC1, ${ }^{9}$ circumstellar envelopes $(\mathrm{CSE}),{ }^{10}$ photodissociation regions (PDR), ${ }^{11}$ hot cores, ${ }^{12}$ protostar regions, ${ }^{13}$ protoplanetary nebulae ${ }^{14}$ and molecular outflows. ${ }^{15}$ It has even been detected in other galaxies. ${ }^{16}$ Acetonitrile is an important molecule in astrochemistry because it is believed to be a link in the chain of chemical processes leading to formation of amino acids. ${ }^{17}$

The chemical reactivity of $\mathrm{CH}_{3} \mathrm{CN}$ is of great interest for all these gas phase environments. In the Earth's troposphere the main chemical sink for $\mathrm{CH}_{3} \mathrm{CN}$ is provided by its slow reaction with $\mathrm{OH}$, which has been studied by many groups, both experimentally ${ }^{18-23}$ and theoretically. ${ }^{24-26}$ Although the rate coefficient at room temperature is small $\left(\approx 2 \times 10^{-14} \mathrm{~cm}^{3}\right.$ molecule $\left.\mathrm{e}^{-1}\right)$, it is at least one order of magnitude larger than that for its reaction with the other main oxidants $\mathrm{Cl}^{19,20,22,27-30}$ and $\mathrm{NO}_{3}{ }^{31}$ In the stratosphere, additional reactions have been considered involving the oxygen atom in its ground $O\left({ }^{3} \mathrm{P}\right)$ and metastable state $O\left({ }^{1} D\right),{ }^{22,32}$ for which a few laboratory works are available for $\mathrm{O}\left({ }^{3} \mathrm{P}\right)^{33-35}$ and for $\mathrm{O}\left({ }^{1} \mathrm{D}\right) \cdot{ }^{36} \mathrm{It}$ is interesting to note as well that acetonitrile is strongly involved in the cation chemistry taking place in the stratosphere. Indeed, the presence of the important class of cluster ions $\mathrm{H}^{+} \mathrm{CH}_{3} \mathrm{CN}\left(\mathrm{H}_{2} \mathrm{O}\right)_{n}$ discovered and identified thirty years ago ${ }^{37}$ was attributed to the reaction of proton hydrates $\mathrm{H}^{+}\left(\mathrm{H}_{2} \mathrm{O}\right)_{n+1}$ with $\mathrm{CH}_{3} \mathrm{CN}^{38}$ a process experimentally studied by Smith et al. ${ }^{39}$ and Viggiano et al. ${ }^{40}$

Since the pioneering work by Yung et al. ${ }^{41}$ in the eighties, many chemical networks have been developed to match observations in the atmosphere of Titan. In one of the most recent ones, 
Loison et al. ${ }^{42}$ discuss the neutral photochemistry and suggest that acetonitrile is essentially produced by the association reaction $\mathrm{H}+\mathrm{CH}_{2} \mathrm{CN}+\mathrm{M} \rightarrow \mathrm{CH}_{3} \mathrm{CN}+\mathrm{M}$, for which they have calculated the rate coefficient based on a semi empirical model. ${ }^{43}$ The model, however, includes several other reactions leading to acetonitrile, namely: $\mathrm{NH}+\mathrm{C}_{2} \mathrm{H}_{3} ; \mathrm{CH}+\mathrm{CH}_{2} \mathrm{NH} ; \mathrm{H}$ or $\mathrm{C}_{2} \mathrm{H}_{3}$ or $\mathrm{C}_{2} \mathrm{H}_{5}+\mathrm{CH}_{2} \mathrm{CN}$ and finally c- $\mathrm{CH}_{2} \mathrm{NCH}+\mathrm{H}$, for which no laboratory data are available. The reactivity of most of these processes was then estimated or calculated by the authors. The main sink for acetonitrile is expected to be photodissociation, although several reactions with radicals $\left(\mathrm{N}\left({ }^{2} \mathrm{D}\right)\right.$, $\mathrm{CH}, \mathrm{C}_{2} \mathrm{H}_{3}, \mathrm{H}, \mathrm{C}_{2} \mathrm{H}$ and $\mathrm{CN}$ ) have also been included in the model. Only the reactions of $\mathrm{CH}_{3} \mathrm{CN}$ with the last three radicals are documented. $\mathrm{H}+\mathrm{CH}_{3} \mathrm{CN}$ has been studied experimentally ${ }^{44}$ and theoretically ${ }^{45,46}$ as has $\mathrm{C}_{2} \mathrm{H}+\mathrm{CH}_{3} \mathrm{CN}{ }^{47-49} \mathrm{CN}+\mathrm{CH}_{3} \mathrm{CN}$ has only been studied experimentally by Zabarnick and $\mathrm{Lin}^{50}$ For the first three radicals the authors estimated or calculated the rate coefficients. In ionospheric models, such as those developed by Krasnopolsky, ${ }^{51}$ some reactions with cations $\left(\mathrm{HCNH}^{+}, \mathrm{C}_{2} \mathrm{H}_{5}^{+}\right)$are also sink processes for $\mathrm{CH}_{3} \mathrm{CN}$.

In the interstellar medium, gas phase formation of $\mathrm{CH}_{3} \mathrm{CN}$ is anticipated to come from three processes: $\mathrm{CN}^{-}+\mathrm{CH}_{3} \rightarrow \mathrm{CH}_{3} \mathrm{CN}+\mathrm{e}^{-}, \mathrm{CH}_{3} \mathrm{CNH}^{+}+\mathrm{e}^{-} \rightarrow \mathrm{CH}_{3} \mathrm{CN}+\mathrm{H}$ and a radiative association mechanism $\mathrm{CN}+\mathrm{CH}_{3} \rightarrow \mathrm{CH}_{3} \mathrm{CN}+$ hv. ${ }^{52-54}$ However, gas-grain chemistry is expected to also provide a significant route for acetonitrile formation either from direct addition of $\mathrm{CH}_{3}$ and $\mathrm{CN}$ or from successive hydrogenations starting with $\mathrm{C}_{2} \mathrm{~N}^{55}$ It is worth noting here that laboratory experiments on ice analogs demonstrated quite recently that acetonitrile can be formed via VUV irradiation of a pure ethylamine $\left(\mathrm{C}_{2} \mathrm{H}_{5} \mathrm{NH}_{2}\right)$ ice maintained at $20 \mathrm{~K},{ }_{1}^{17}$ a route not presently considered in astrochemical networks to our knowledge. Further evaporation of the grain surface can then release $\mathrm{CH}_{3} \mathrm{CN}$ in the gas phase environment provided that the grain surface is heated up to about $90 \mathrm{~K}$. On the other hand, potential processes for destruction of acetonitrile include dissociation and ionization by cosmic rays or photons and a large number of ion- $\mathrm{CH}_{3} \mathrm{CN}$ reactions (see the KIDA and the UMIST rate12 databases at respectively http:// http://kida.obs.u-bordeaux1.fr and http://udfa.ajmarkwick.net/ for details).

As indicated in this brief overview of acetonitrile chemistry, its gas phase reactivity with neutral radicals of interest for a very diverse set of natural environments has been the subject of a considerable number of laboratory studies. The radicals studied include $\mathrm{OH}, \mathrm{Cl}, \mathrm{NO}_{3}, \mathrm{O}\left({ }^{3} \mathrm{P}\right)$, $\mathrm{O}\left({ }^{1} \mathrm{D}\right), \mathrm{H}, \mathrm{C}_{2} \mathrm{H}$ and $\mathrm{CN}$. To be completely exhaustive we must state that some studies involving bromine, ${ }^{30}$ fluorine, ${ }^{29,56-58}$ and nitrogen ${ }^{59}$ atoms, $\mathrm{CD}_{3}{ }^{60}$ and $\left(\mathrm{CH}_{3}\right)_{3} \mathrm{CO}^{61}$ are also available in the literature.

One striking aspect of these prior studies of $\mathrm{CH}_{3} \mathrm{CN}$ chemistry is the lack of data at low temperatures. Only three works have been carried out below $200 \mathrm{~K}$. One study deals with the $\mathrm{O}\left({ }^{1} \mathrm{D}\right)+\mathrm{CH}_{3} \mathrm{CN}$ reaction, which was investigated in the temperature range $193-430 \mathrm{~K}^{36}$ The other two consider the $\mathrm{C}_{2} \mathrm{H}+\mathrm{CH}_{3} \mathrm{CN}$ reaction. Nizamov \& Leone ${ }^{48}$ measured the rate coefficient in the temperature range $165-296 \mathrm{~K}$, whereas Sun et al. ${ }^{49}$ predicted the rate coefficient and 
branching ratios for temperature ranging from $150-3000 \mathrm{~K}$ using a combination of ab initio electronic structure theory, transition state theory (TST) and multichannel RRKM theory.

Some recent studies by Shannon and coworkers ${ }^{62-65}$ have explored the related low temperature kinetics of $\mathrm{OH}$ radicals reacting with a variety of oxygenated volatile organic compounds. These studies have illuminated important roles for collisional stabilization of a van der Waals complex (between the two reactants) and for tunneling induced abstraction reactions. Both effects contribute to a dramatic increase in the rate coefficient for overall loss at low temperature. The low temperature kinetics of acetonitrile reacting with strong abstractors might be expected to show similar behavior.

In the present investigation, we have focused our interest on the reaction between $\mathrm{CH}_{3} \mathrm{CN}$ and the cyanide radical $\mathrm{CN}$, which is isoelectronic with $\mathrm{C}_{2} \mathrm{H}$. As mentioned above, only one study has been carried out previously. Zabarnick and $\operatorname{Lin}^{50}$ used a pyrex reaction cell which could be resistively heated in order to measure the rate coefficient at 297,380 , and $578 \mathrm{~K}$ in a 20 Torr argon buffer. The PLP-LIF (Pulsed Laser Photolysis - Laser Induced Fluorescence) technique was used to first produce the $C N$ radical from laser photolysis of ICN and then detect its fluorescence after a dye laser excitation of the $Q_{1}(5)$ transition of the $A^{2} \Pi-X^{2} \Sigma^{+}(4,0)$ band at $621.5 \mathrm{~nm}$. They observed Arrhenius behavior, with the temperature dependence of the rate coefficient $k_{\text {zab }}$ fitted by the expression:

$$
k_{Z a b}=\left(6.46 \pm \begin{array}{l}
1.66 \\
1.33
\end{array}\right) \times 10^{-11} \exp \frac{-1190 \pm 70}{T} \mathrm{~cm}^{3} \operatorname{molec}^{-1} \mathrm{~s}^{-1}
$$

At room temperature, their measurement gave a small rate coefficient of $(11.2 \pm 3.0) \times 10^{-13} \mathrm{~cm}^{3}$ molecule ${ }^{-1} \mathrm{~s}^{-1}$. No information was available concerning the products of the reaction and the authors only mentioned the following exothermic channels as potential pathways:

$$
\mathrm{CN}+\mathrm{CH}_{3} \mathrm{CN} \rightarrow \begin{cases}\mathrm{C}_{2} \mathrm{~N}_{2}+\mathrm{CH}_{3} & \Delta \mathrm{H}=-14.1 \mathrm{kcal} / \mathrm{mol} \\ \mathrm{HCN}+\mathrm{CH}_{2} \mathrm{CN} & \Delta H=-29.3 \mathrm{kcal} / \mathrm{mol}\end{cases}
$$

Using the CRESU technique (see below) and a conventional slow flow reaction cell we have performed a series of experiments in the temperature range $23-354 \mathrm{~K}$ for pressures ranging from 0.16 to 80 mbar. These experiments observe an interesting temperature and pressure dependence of the rate coefficient for the total loss of $\mathrm{CN}$ radical. Complementary ab initio transition state theory based master equation calculations aid in the interpretation of these observations. These calculations include high accuracy explorations of the possible reaction pathways and detailed consideration of the role of collisional stabilization of a $\mathrm{CN}_{\text {.... }} \mathrm{CH}_{3} \mathrm{CN}$ van der Waals complex and of tunneling induced $\mathrm{H}$ atom abstractions. Comparison of the experimental measurements with the theoretical predictions yields a convincing description of the interesting behavior observed in the low temperature kinetics of this reaction. 


\section{Methodology}

\subsection{Experimental Details}

Two different apparatuses have been used for the experimental work in order to expand the temperature range covered. Very low temperatures (23 - $168 \mathrm{~K})$ were studied using a continuous uniform supersonic gas expansion generated in a CRESU (a French acronym standing for "Cinétique de Réaction en Ecoulement Supersonique Uniforme", which translates to "Reaction Kinetics in a Uniform Supersonic Flow") chamber. The method, which was developed 30 years ago, has been explained in detail elsewhere ${ }^{66-68}$ so that only a brief summary will be reported below, emphasizing only the specifics of the present study. The supersonic flow is generated by expanding a buffer gas from a high pressure reservoir $P_{0}$, to a low pressure chamber $P_{c h}$ after passing through a Laval nozzle that represents the heart of the technique. To maintain uniformity along several tens of a centimeter, large flow rates are usually required (typically: $Q_{\text {Gas }}=50$ standard liters per minute $(\mathrm{s} / \mathrm{m})$ ) and hence large pumping capacities in order to keep the downstream pressure low. Values ranging from 0.1 to 6 mbar can be achieved with the installation available in Rennes, which delivers a pumping rate of $24000 \mathrm{~m}^{3} / \mathrm{h}$. The physical conditions (temperature $T$, pressure $P$, velocity) in the uniform supersonic flow depend on the Laval nozzle geometric profile, the buffer gas (argon or helium in the present work), and the flow rate so that a series of nozzles is required to explore a given temperature and pressure range. Sometimes, however, a given geometric profile can generate good uniform supersonic flows for several discrete sets of conditions. ${ }^{69,70}$

The highest temperatures (258 - $354 \mathrm{~K}$ ) were achieved using a standard stainless steel cylindrical cell (cryocell hereafter) through which a slow gas flow (argon or helium) passes. The cell is surrounded by a copper tube in order to regulate the temperature using an adequate fluid circulating by means of a cryostat (Lauda RP 890 (C)). In the present work, water was used to heat the cell up to $354 \mathrm{~K}$ and ethanol was used to cool it down to $258 \mathrm{~K}$. Temperature into the cell was controlled using thermocouples set at two different positions: one at the gas inlet and the second one slightly downstream of the measurement zone. Pressure in the cell (a few tens of a mbar) was adjusted by manipulating a diaphragm valve (Speedivalve SP25, Edwards) that controls the pumping speed. More details of this device can be found in a recent publication. ${ }^{71}$ The CRESU apparatus was also used in its subsonic configuration to measure rate coefficients at room temperature allowing comparison between the two reactors.

In both reactors, gases (helium U 99.995\% or argon Arcal1 99.995\%, both from Air Liquide) were introduced from cylinders and the flow rates were regulated via passage through calibrated mass flow controllers (MFC). The precursor of CN, lodine Cyanide ICN, is in the form of solid crystals at room temperature. It was placed on a fritted disk stuck to the wall of a pyrex cell inside which a small part of the buffer gas, regulated by a dedicated MFC, passed through 
entraining the vapors of ICN into the main chamber (CRESU reservoir or cryocell). To introduce acetonitrile (purity 99\%, Sigma Aldrich) into the cryocell, a separate 20 liters homemade stainless steel cylinder was filled at a precisely measured pressure of $\mathrm{CH}_{3} \mathrm{CN}$ vapor, which was then diluted into a buffer gas at a typical total pressure of 2 bar. The dilution factor in the experiments ranged from 3 to $4 \%$. This mixture was then passed through a MFC before entering the cryocell. This method was also sometimes used in the CRESU apparatus with a dilution factor of $10 \%$, but for the vast majority of individual CRESU experiments, a bubbler system, similar to that described elsewhere, ${ }^{72}$ was preferred. To avoid cooling of acetonitrile when a significant flow rate of buffer gas bubbled into the liquid, the phial containing this liquid was immersed into a bath of water maintained at about $30^{\circ} \mathrm{C}$, a temperature slightly higher than in the laboratory. Pressure and (room) temperature at the exit of the bubbler condensation column were precisely measured (using a 1000 torr MKS baratron and a thermocouple, respectively) in order to determine both the vapor pressure of acetonitrile entrained by the buffer gas and the partial flow rate of acetonitrile prior to entering the reservoir. The vapor pressure $P_{v s}$ of acetonitrile was calculated using Antoine's law obtained by Dojcansky and Heinrich ${ }^{73}$ in the temperature range $15<T<89^{\circ} \mathrm{C}$ :

$$
\log P_{v S}(\text { Torr })=7.27748-\frac{1424.472}{T\left({ }^{\circ} C\right)+242.202}
$$

From the known total density $n_{\text {tot }}$ in the reactor flow and the different gas flow rates, the partial concentration of acetonitrile $\left[\mathrm{CH}_{3} \mathrm{CN}\right.$ ] (in units of molecule $\mathrm{cm}^{-3}$ ) can be deduced for the cryocell or for the uniform supersonic flow.

Both reactors were coupled to the PLP-LIF technique using the same pair of lasers to generate and detect the cyanide radical. Two retractable mirrors allowed us to easily propagate lasers either inside the cryocell in a perpendicular configuration or along the uniform supersonic flow axis colinearly. CN radicals were then produced by photolysis of ICN at $266 \mathrm{~nm}$ using a Nd-YAG laser pulsed at $10 \mathrm{~Hz}$ (Spectra Physics GCR 190, $60 \mathrm{~mJ} /$ pulse). The CN radical was then excited at ca. $387 \mathrm{~nm}\left((0,0)\right.$ band of the electronic transition $\left.\mathrm{B}^{2} \Sigma^{+}-\mathrm{X}^{2} \Sigma^{+}\right)$by a second laser beam issued from a dye laser (ND 6000 Continuum) pumped by a $10 \mathrm{~Hz}$ Nd-YAG laser working at $355 \mathrm{~nm}$ (Spectra Physics GCR 230, $70 \mathrm{~mJ} /$ pulse). Exalite 389 dye diluted in dioxane was used to generate the $387 \mathrm{~nm}$ wavelength, delivering a typical energy of $0.4 \mathrm{~mJ} /$ pulse at the exit of the dye laser. Fluorescence issued from the $(0,1)$ band of the $\mathrm{B}^{2} \Sigma^{+}-\mathrm{X}^{2} \Sigma^{+}$transition at $c a .421 .6 \mathrm{~nm}$ was then collected perpendicularly to the flow axis through a collimating optical system, an interference filter (420 nm, $10 \mathrm{~nm}$ FWHM), and a photomultiplier tube PMT (Electron Tubes 9128QB for the cryocell and Thorn EMI, 6773 for the CRESU apparatus). Both lasers penetrate inside and exit the reactors through quartz windows set at Brewster's angle. A third Brewster angle window was used at the entry of the reservoir in the CRESU apparatus in order to compensate for the refraction induced by the quartz window set at the entrance of the chamber. 
A delay generator DG (BNC-565 for the cryocell and DG 535 Stanford Research System for the CRESU) was used to fix the delay time between the photolysis and the probe pulses. The fluorescence signal decreases exponentially when the delay time increases because more time is available for the reactive processes to proceed and destroy the $\mathrm{CN}$ radical. The output signal issued from the PMT was sent to a boxcar integrator (SR 250 Stanford Research System). A ramp of delay times $t$ was generated by a homemade Labview program and sent to the DG, whereas the boxcar signal was collected for each delay time. Then, a series of traces $S(t)$ were recorded and computer analyzed. These traces were fitted by an exponential function of the form:

$A_{0} \exp ^{-k_{s t} t}+b$, where $k_{s t}$ is the so-called pseudo-first order rate coefficient (in units $s^{-1}$ ), which depends linearly on $\left[\mathrm{CH}_{3} \mathrm{CN}\right]$. To improve the quality of the traces and thus the accuracy of the $k_{s t}$ determination, a series of 6 to 10 temporal ramps were recorded for each acetonitrile concentration. The slope of the straight line obtained from plots of $k_{s t}$ as a function of $\left[\mathrm{CH}_{3} \mathrm{CN}\right]$ directly yields the second order rate coefficient $k(T)$ (in units of $\mathrm{cm}^{3}$ molecule ${ }^{-1} \mathrm{~s}^{-1}$ ) at the temperature of the flow.

\subsection{Theoretical Methods}

\section{Reaction Pathways}

The stationary points on the $\mathrm{CN}+\mathrm{CH}_{3} \mathrm{CN}$ potential energy surface were explored with two separate methodologies. In the first method, the geometries were optimized using the hybrid generalized gradient approximation (GGA) B3LYP functional ${ }^{74}$ with the Pople-style triple-zetavalence basis set with one d-type polarization function $6-311 G(d, p)$. Harmonic vibrational analyses were performed at the same level of theory to confirm each stationary point as either an equilibrium structure (i.e., all real frequencies) or a transition structure (TS) (i.e., with one imaginary frequency). Zero-point vibrational energy (ZPVE) corrections have been obtained from such calculations as one-half the sum of the harmonic frequencies, and have been used to correct the electronic energies. The connectivities of the transition structures were confirmed by performing intrinsic reaction coordinate (IRC) calculations as necessary. ${ }^{75}$

More reliable reaction energies and barrier heights, were obtained with the Gaussian-4 (G4) thermochemical protocol ${ }^{76}$ starting from these B3LYP/6-311G(d,p) geometries. The G4 protocol is widely used for the calculation of accurate thermochemical and kinetic properties. Specifically, G4 obtains mean absolute deviations (MADs) from reliable experimental thermochemical data below the threshold of "chemical accuracy" (arbitrarily defined as 1 $\mathrm{kcal} / \mathrm{mol}) .{ }^{77}$ For example, for the 454 experimental thermochemical determinations of the G3/05 test set (including heats of formation, ionization energies, and electron affinities), G4 attains a MAD of $0.83 \mathrm{kcal} / \mathrm{mol}^{76}$ All the geometry optimizations, frequency and G4 calculations 
for this first method were performed using the Gaussian 09 program suite ${ }^{78}$ (see also: http:www.gaussian.com).

The G4 protocol is based on B3LYP/GTBas3 rovibrational analyses. The B3LYP functional often has difficulty in locating the saddle point for low barrier processes due to its tendency to underestimate barrier heights. The use of coupled cluster methods in the rovibrational analyses and the implementation of larger basis sets and additional corrections in advanced electronic structure methods such as $\mathrm{HEAT}^{79}$ and $\mathrm{W}^{80}{ }^{80}$ results in even higher accuracy predictions than the G4 protocol. At low temperatures, kinetic predictions are strongly dependent on the underlying electronic energies. Thus, we have also explored the stationary points on the potential energy surface (PES) with an alternative method that is analogous to the HEAT and W4 methods.

For this higher level method, the rovibrational properties were determined at the CCSD(T)/ccpVTZ level. High level (HL) energy estimates were obtained from estimates for (i) the CCSD(T) complete basis set (CBS) limit obtained from extrapolation of calculations for the aug'-cc-pVQZ and aug'-cc-pV5Z basis sets, (ii) higher order corrections from CCSDT(Q)/cc-pVDZ calculations, (iii) core-valence corrections from $\operatorname{CCSD}(\mathrm{T}$,full)/CBS calculations based on extrapolation of results for the cc-pcVTZ and cc-pcVQZ basis sets, (iv) relativistic corrections from $\mathrm{Cl} /$ aug-ccpcVTZ calculations, and $(v)$ anharmonic zero-point energy (ZPE) corrections calculated at the $B 3 L Y P / 6-311++G(d, p)$ level. For this $H L$ method, we estimate $2 \sigma$ uncertainties in the predicted 0 $\mathrm{K}$ heat of formation of $0.3 \mathrm{kcal} / \mathrm{mol}$.

Each of the CBS extrapolations were based on a two-point $I /(I+1)^{4}$ formula. ${ }^{81}$ The Dunning correlation consistent basis sets ${ }^{82,83}$ were employed throughout the analysis. For the aug'-cc$\mathrm{pVnZ}$ bases the prime indicates that diffuse functions are included for only the $s$ and $p$ orbitals in $\mathrm{C}$ and $\mathrm{N}$ and the $\mathrm{s}$ function in $\mathrm{H}$. The $\operatorname{CCSD}(\mathrm{T})$ calculations generally employed RHF wavefunctions within the UCCSD(T) formalism implemented in MOLPRO. ${ }^{84}$ The CCSDT(Q) calculations instead employed UHF wavefunctions as required by the MOLPRO implementation of Kallay's ${ }^{\dagger}$ MRCC code. ${ }^{85}$

The B3LYP and CCSD(T)/cc-pVTZ analyses predict somewhat different topography for the longrange van der Waals portion of the potential energy surface. These differences appear to be indicative of the very weak orientational dependence of the interactions, which leads to a strong basis set dependence for the location of the minima. Thus, we have also explored the stationary point properties in the van der Waals region with the CCSD(T)-F12/cc-pVDZ-F12 method. ${ }^{86,87}$ The F12 method yields improved basis set convergence and for this system yields slightly lower $\operatorname{CCSD}(\mathrm{T}) / \mathrm{CBS}$ absolute energy estimates, suggesting that the geometries are indeed improved over the CCSD(T)/cc-pVTZ ones.

\footnotetext{
${ }^{\dagger}$ MRCC, a String-Based Quantum Chemical Program Suite; written by M. Kallay
} 
The B3LYP/GTBas3, CCSD(T)/cc-pVTZ and CCSD(T)-F12/cc-pVDZ-F12 optimized geometries and vibrational frequencies for the stationary points in the $\mathrm{CN}+\mathrm{CH}_{3} \mathrm{CN}$ reaction are reported in the Supporting Information.

\section{Kinetics}

Predictions for the temperature and pressure dependent rate coefficients for reactions proceeding through the $\mathrm{CH}_{3} \mathrm{CN}$...CN van der Waals complex were obtained with the ab initio transition state theory based master equation (AITSTME) approach. ${ }^{88}$ The implementation of this AITSTME analysis requires estimates for the reactant partition functions, the density of states of the $\mathrm{CH}_{3} \mathrm{CN}$...CN van der Waals complex, the transition state numbers of states for the entrance and exit channels from this complex, and the kernel for collisional energy transfer within the van der Waals complex. The MESS code was used in the present kinetic analyses. ${ }^{89}$

In typical pressure dependent kinetic analyses the stabilization occurs to a strongly bound chemical complex. Here we are interested in the stabilization of a weakly bound van der Waals complex, which presents interesting complications for the analysis. First, the density of states of the $\mathrm{CH}_{3} \mathrm{CN}$...CN complex is not well modeled with rigid-rotor harmonic oscillator (RRHO) assumptions. Furthermore, the standard representations for collisional energy transfer may not be applicable. Finally, the evaluation of the entrance flux must focus on the long-range potential.

The effect of anharmonicities on the $\mathrm{CN}$... $\mathrm{CH}_{3} \mathrm{CN}$ state densities is not readily accounted for via simple hindered rotor treatments due to the presence of multiple distinct minima on the PES in the van der Waals region. Here, we have instead evaluated such anharmonic effects via Monte Carlo based evaluations of the classical phase space representation of the density of states. Within these evaluations we focussed on the intermolecular (or transitional) modes of the complex, and employed direct MP2/cc-pVTZ ab initio evaluations of the interaction energies for two rigidly interacting fragments. The calculations employ a radial cutoff of $8 \AA$, with larger separations roughly correlating with geometries that lie outside the transition state for dissociation back to $\mathrm{CN}+\mathrm{CH}_{3} \mathrm{CN}$. A total of 20,000 sampling points were employed, yielding statistical uncertainties of $\sim 4 \%$ near the dissociation threshold. Sample calculations suggest that the classical representation introduces minimal errors due to the low frequency nature of the intermolecular modes.

The full density of states for $\mathrm{CN}$.... $\mathrm{CH}_{3} \mathrm{CN}$ is obtained through convolution of this transitional mode state density with the density of vibrational modes for $\mathrm{CN}$ and $\mathrm{CH}_{3} \mathrm{CN}$. The weak bonding nature of the van der Waals complex suggests that such mode separation approximations are appropriate. Indeed, constrained optimizations, where the $\mathrm{CN}$ and $\mathrm{CH}_{3} \mathrm{CN}$ are held rigid at their asymptotic structures, yield binding energies that are within $0.02 \mathrm{kcal} / \mathrm{mol}$ of the energies for 
the fully optimized structure. The MP2/cc-pVTZ binding energies of 3.65 and $3.33 \mathrm{kcal} / \mathrm{mol}$ for the nonlinear and linear complexes are in reasonable agreement with the $\mathrm{HL}$ values of 3.05 and $3.01 \mathrm{kcal} / \mathrm{mol}$ (all before ZPE corrections). Limited CCSD(T)/cc-pVDZ and MP2/cc-pVDZ suggest that the MP2/cc-pVTZ predicted state density should be reasonably well estimated (within a factor of 1.5), at least near the dissociation threshold, which is where this value affects the rate predictions.

The transition state flux for the formation of the van der Waals complexes from the reactants was obtained with variable reaction coordinate transition state theory (VRC-TST). ${ }^{90,91}$ The VRCTST approach requires some specification of the interaction between the two reactants at arbitrary separation and orientation. Here, those interaction energies were obtained from direct MP2/cc-pVQZ evaluations. Calculations employing direct MP2/cc-pVTZ energies yielded results that differ by less than $5 \%$, suggesting that the calculations are well converged with respect to basis set. Furthermore, calculations employing CCSD(T)/cc-pVDZ and MP2/cc-pVDZ energies agreed to within $10 \%$, suggesting that the MP2 method is adequate for the evaluation of this flux. The configurational integrals involved in the VRC-TST calculations were converged to within $5 \%$ statistical integration uncertainties. The reaction coordinate was assumed to be the separation between the $\mathrm{CN}$ and $\mathrm{CH}_{3} \mathrm{CN}$ centers-of-mass, which is generally appropriate for longrange transition states. The final results employ a dynamical correction factor of 0.85 , which accounts for typical overestimates of the reactive flux within VRC-TST.

The collisional energy transfer kernel should describe the rate and distribution of energy transitions in $\mathrm{CN}$... $\mathrm{CH}_{3} \mathrm{CN}$ arising from collisions with $\mathrm{Ar}$ bath gas atoms. For simplicity, we have employed standard exponential down energy transfer probabilities and Lennard-Jones collision rates. However, it is not clear what parameters to employ in these representations or even whether these representations are appropriate for this system. One might well imagine that the collision of bath gas molecules with a van der Waals complex leads to a significantly higher probability than normal of chattering collisions with multiple interactions between the bath and the two, more or less decoupled, parts of the complex. Such chattering collisions would have larger average energy transfer and will likely become even more probable with decreasing temperature. Thus, the average downwards energy transferred, $\left\langle\Delta \mathrm{E}_{\mathrm{d}}\right\rangle$, was set to $800 \mathrm{~cm}^{-1}$ independent of temperature, which is perhaps two or three times what one would ordinarily have postulated for room temperature. Also, the correct molecular size to use for a fluxional van der Waals molecule is rather unclear. As a first approximation we use a $\sigma$ value of $8 \AA$ for the $\mathrm{CN}$.... $\mathrm{CH}_{3} \mathrm{CN}$ complex and $\varepsilon$ was taken to be $400 \mathrm{~cm}^{-1}$. For Ar the Lennard-Jones parameters $\sigma$ and $\varepsilon$ were set to $3.47 \AA$ and $79 \mathrm{~cm}^{-1}$, respectively. Clearly, there is considerable ambiguity in our treatment of the energy transfer kernel and in the end we examine the effects of varying $\sigma$ for $\mathrm{CN}$... $\mathrm{CH}_{3} \mathrm{CN}$ as a way to adjust the effective energy transfer rates. 
The exit channels to produce the chemical complexes $\mathrm{CH}_{3} \mathrm{CNCN}$ and $\mathrm{NCC}\left(\mathrm{CH}_{3}\right) \mathrm{N}$ and the abstraction to produce $\mathrm{CH}_{2} \mathrm{CN}+\mathrm{HCN}$ were treated with tunneling corrected variational RRKM theory. The energies and rovibrational properties along the IRC were obtained with the B2PLYP3/cc-pVTZ method, which accurately reproduces the CCSD(T)/cc-pVTZ properties at the saddle point for the formation of $\mathrm{NCC}\left(\mathrm{CH}_{3}\right) \mathrm{N}$ (i.e., the transition state partition function is reproduced to within $10 \%$ ) and provides a reasonably satisfactory treatment of the other less important channels. The saddle point energy was taken from the HL analysis. The asymmetric Eckart model was employed in estimating tunneling corrections. In each case, rigid-rotor harmonic oscillator (RRHO) assumptions were employed for all but the $\mathrm{CH}_{3}$ torsional mode, which was treated as a one-dimensional hindered rotor. The abstraction to produce $\mathrm{CH}_{2} \mathrm{CN}+$ $\mathrm{HCN}$ was treated with tunneling corrected RRKM theory with no variational analysis since it was found to be relatively unimportant.

\section{Results and Discussion}

\subsection{Experiments}

Results concerning the $k(T, P)$ measurements are reported in Tables 1 (CRESU data) and 2 (cryocell data) and are plotted in Figs. 1, 2a and 2b. The uncertainties indicated in the last column on the right of Tables 1 and 2 correspond to the square root of the sum of the statistical and systematic errors squared. Statistical errors are calculated by applying a least-squares analysis to the $k_{s t}$ vs. $\left[\mathrm{CH}_{3} \mathrm{CN}\right]$ representations. The obtained standard deviation is then multiplied by the Student's t-factor appropriate for the $95 \%$ statistical confidence limit and the number of degrees of freedom. Systematic errors come from instrumentation mainly, including pressure gauges and MFCs, combined with uncertainties in the $\mathrm{CH}_{3} \mathrm{CN}$ vapor pressure data. Every effort was made to minimize these by regular calibrations of MFCs and pressure gauges. After each $\left[\mathrm{CH}_{3} \mathrm{CN}\right]$ change and before each recording of $S(t)$ traces, the temperature at the exit of the bubbler column was checked in order to minimize the effect of temperature fluctuations in the laboratory room on the $\mathrm{CH}_{3} \mathrm{CN}$ vapor pressure calculation. Therefore, systematic errors were reasonably estimated to be about $10 \%$.

Fig. 1 shows the temperature evolution of a significant sample of rate coefficients measured in the CRESU chamber (identified in Table 1 by an asterisk) and all the data obtained with the cryocell device. The previous work from Zabarnick and $\mathrm{Lin}^{50}$ is presented as well. The most striking aspect of this figure is the dramatic change in behavior of the rate coefficient with temperature. Three very different ranges can be identified. At temperatures greater than say $200 \mathrm{~K}$, a quite standard Arrhenius behavior is observed in qualitative agreement with the study of Zabarnick and Lin. This result clearly indicates that an activation barrier is present along the reaction path from reactants to products. Below $200 \mathrm{~K}$, we observe a very sharp increase (a 
factor of 130 !) of the rate coefficient when the temperature diminishes from 168 to $123 \mathrm{~K}$, demonstrating that the nature of the reactive process changes radically. Below $123 \mathrm{~K}, k(T)$ continues to increase, but only by a factor of about 2 between 123 and $23 \mathrm{~K}$.

To obtain more insight into these observations, the pressure dependence of the rate coefficient was explored at a few different temperatures. At $297 \mathrm{~K}$, several measurements have been carried out using both reactors and for different buffer gases and pressures (5 - 80 mbar) leading to the conclusion that the rate coefficient is not pressure dependent at this temperature. A typical value of $3 \times 10^{-13} \mathrm{~cm}^{3}$ molecule ${ }^{-1} \mathrm{~s}^{-1}$ was found for $k(297 \mathrm{~K})$. At $132 \mathrm{~K}$, four experiments were performed for total densities of argon ranging from $3.4 \times 10^{16}$ to $16.5 \times 10^{16} \mathrm{~cm}^{-}$ ${ }^{3}$ (almost a factor of 5). These data are plotted in Fig. 2a, with an expanded view provided in Fig. 2b. Here, the rate coefficient clearly appears to depend linearly on the total density (i.e. pressure) and increases by about a factor of three over the studied density range. This behavior strongly suggests that an adduct is formed in the reaction pathway and that our measurements are in the low pressure regime of the fall-off curve characteristic of pressure dependent processes. Interestingly, the straight line fitting the experimental data does not extrapolate to zero rate constant when extrapolated to null density. This may suggest that two processes are competing, with one of them independent of pressure. We will return to this point later in the paper. At $52 \mathrm{~K}$, six experiments have been achieved exploring an extensive density range of argon, $(3.5-82.1) \times 10^{16} \mathrm{~cm}^{-3}$, over which the rate coefficient increases significantly from $3.2 \times 10^{-11}$ to $12.2 \times 10^{-11} \mathrm{~cm}^{3}$ molecule ${ }^{-1} \mathrm{~s}^{-1}$. A classic fall-off curve was obtained in this case confirming the presence of an adduct along the reaction path. Extrapolation to smaller densities was somewhat uncertain, however, because of some dispersion of the data. Finally, at $23 \mathrm{~K}$, two experiments were carried out at densities of helium differing by a factor of almost 4 and measurements were found to be identical within the error bars.

From these observations, the data presented in Fig. 1 deserve some additional comments. As can be seen in Table 1 (column 2), the total densities were not the same for each experiment. Thus, it is not possible to extract from Fig. 1 a correct temperature dependence because part of the behavior can be attributed to differences in the total densities. However, almost all the data $(\sim 80 \%)$ plotted in Fig. 1, below $200 \mathrm{~K}$, correspond to total densities between $5 \times 10^{16}$ and $13 \times 10^{16}$ $\mathrm{cm}^{-3}$, with the exception of measurements at $24.1,88.3$, and $97.4 \mathrm{~K}$. To minimize this effect, at 52 and $132 \mathrm{~K}$, the plotted data have been chosen so that the corresponding total density was as close as possible to adjacent data. Finally, the tremendous increase (factor of 130) in the rate coefficient between 168 and $123 \mathrm{~K}$ cannot be attributed to a difference in the total density as this varies by less than a factor of $2\left(6.9 \times 10^{16}\right.$ to $\left.12.7 \times 10^{16} \mathrm{~cm}^{-3}\right)$ for all measurements performed over this temperature range.

To gain deeper insight into the mechanisms involved in this reaction, we have performed a detailed theoretical kinetic analysis. In the next section, we first present the results of our 
exploration of the PES, considering the role of both abstraction and addition reaction pathways. Then, predictions of the pressure and temperature dependence of the rate coefficient will be detailed and compared to experimental data.

\subsection{Calculations}

\section{Reaction pathways}

A schematic diagram of the low energy reaction paths for the reaction of $\mathrm{CN}$ with $\mathrm{CH}_{3} \mathrm{CN}$ is provided in Fig. 3. The corresponding G4 and HL stationary point energies are reported in Table 3. The theoretical analyses suggest the presence of perhaps three distinct van der Waals complexes: linear and bent $\mathrm{CH}_{3} \mathrm{CN}$...CN complexes and a linear $\mathrm{NC}^{2 . . .} \mathrm{CH}_{3} \mathrm{CN}$ complex. The paths connecting these van der Waals complexes have saddle points that lie well below the $\mathrm{CN}+$ $\mathrm{CH}_{3} \mathrm{CN}$ asymptote. Furthermore, whether or not each of these structures is a minimum depends to some extent on the level of theory applied. In the kinetic analysis we simply consider these complexes to be rapidly equilibrated and evaluate the density of states for the global van der Waals region.

The lowest energy reaction path from the van der Waals complex involves the addition of the $\mathrm{CN}$ radical to the central $\mathrm{C}$ of $\mathrm{CH}_{3} \mathrm{CN}$ to form the $\mathrm{NCC}\left(\mathrm{CH}_{3}\right) \mathrm{N}$ complex. This chemical complex may then dissociate at energies below the $\mathrm{CN}+\mathrm{CH}_{3} \mathrm{CN}$ asymptote to form $\mathrm{CH}_{3}+\mathrm{NCCN}$. Alternatively, the barrier for the addition of $\mathrm{CN}$ to the $\mathrm{N}$ of $\mathrm{CH}_{3} \mathrm{CN}$ to form $\mathrm{CH} 3 \mathrm{CNCN}$ is only 1.1 $\mathrm{kcal} / \mathrm{mol}$ higher in energy. The abstraction barrier to form $\mathrm{HCN}+\mathrm{CH}_{2} \mathrm{CN}$ is another $0.7 \mathrm{kcal} / \mathrm{mol}$ high in energy, while the barrier for abstraction by the $\mathrm{N}$ end of $\mathrm{CN}$ is considerably higher at $12.6 \mathrm{kcal} / \mathrm{mol}$ relative to $\mathrm{CN}+\mathrm{CH}_{3} \mathrm{CN}$.

In general, the title reaction occurs through a competition between stabilization of the $\mathrm{CH}_{3} \mathrm{CN}$...CN complex and further reaction to form the $\mathrm{NCC}\left(\mathrm{CH}_{3}\right) \mathrm{N}$ complex (which perhaps continues on to the $\mathrm{CH}_{3}+\mathrm{NCCN}$ bimolecular fragments). However, at higher temperature the formation of $\mathrm{CH}_{3} \mathrm{CNCN}$ (further dissociation to $\mathrm{CH}_{3}+\mathrm{CNCN}$ does not occur except at quite high temperature as the products are $11 \mathrm{kcal} / \mathrm{mol}$ endothermic) and $\mathrm{HCN}+\mathrm{CH}_{2} \mathrm{CN}$ also make minor contributions to the kinetics. Somewhat counterintuitively, the abstraction to form HNC + $\mathrm{CH}_{2} \mathrm{CN}$ has its greatest significance at low temperatures, due to the large magnitude for its imaginary frequency, which leads to a high tunneling rate. Notably, the reaction through this HNC forming channel bears some similarity to the $\mathrm{NH}_{3}{ }^{+}+\mathrm{H}_{2}$ reaction ${ }^{92}$ where, due to the existence of a pre-barrier complex with a quite large life-time, a small tunneling probability results in the increase of the rate coefficient with diminishing temperature.

The T1 diagnostic, which is a measure of the multi-reference character in the wavefunction, is below 0.03 for each of the stationary points in Table 3, except for $\mathrm{CN}$ and for the abstraction 
transition state leading to $\mathrm{HNC}+\mathrm{CH}_{2} \mathrm{CN}$, where it is near 0.05 . Values above 0.03 generally suggest some concern for $\mathrm{CCSD}(\mathrm{T})$ based evaluations. For $\mathrm{CN}$ we have evaluated a $0 \mathrm{~K}$ heat of formation of $104.12 \mathrm{kcal} / \mathrm{mol}$ with the same $\mathrm{HL}$ methodology using $\mathrm{CH}_{4}, \mathrm{NH}_{3}$, and $\mathrm{H}_{2}$ as references. By comparison the Active ThermoChemical Tables value is $104.38+/-0.03 \mathrm{kcal} / \mathrm{mol}$. (see http://atct.anl.gov/Termochemical Data/version 1.112/) This relatively large discrepancy of $0.26 \mathrm{kcal} / \mathrm{mol}$ is likely a result of multireference effects that arise only for $\mathrm{CN}$, as indicated by the relatively large T1 diagnostic. The smaller T1 diagnostics for the other stationary points, (even the van der Waals complexes) suggest that simply adjusting the $\mathrm{CN}$ energy up by 0.26 $\mathrm{kcal} / \mathrm{mol}$ will provide a reasonably satisfactory adjustment to the potential energy surface. This adjustment is employed in our kinetics evaluations. Although the T1 diagnostic of 0.054 for TS2 also suggests modest multireference effects, it is unlikely that such corrections would dramatically lower this barrier. Notably, the CCSDT(Q)/cc-pVDZ corrections for this TS are within $1 \mathrm{kcal} / \mathrm{mol}$ of those for the other stationary points on the potential energy surface. Thus, we presume that such $\mathrm{CCSDT}(\mathrm{Q}) / \mathrm{cc}-\mathrm{pVDZ}$ corrections adequately capture the multireference effects for this TS.

\section{Rate coefficients}

The present kinetic analysis is closely related to the master equation based study of $\mathrm{OH}+$ acetone and dimethyl ether presented by Shannon et al. $2014 .{ }^{65}$ The analysis generalizes the two TS description of Greenwald et al..$^{93}$ to include a variety of chemical exit channels including two addition channels and two abstraction channels (cf. Fig. 3). The kinetics involves a transition from stabilization of the long-range van der Waals complex (at low temperatures) to chemical reaction (at higher temperatures), with a possible role for tunneling induced reactions in the low pressure limit. A useful qualitative description of this competition was provided in a recent study of $\mathrm{OH}+$ ethanol and propanol by Caravan et al. ${ }^{62}$ Here, we focus on a direct comparison of theoretical predictions with the experimental data for the title reaction.

The predicted pressure dependence for the $\mathrm{CN}$ loss rate coefficient from the present theoretical analysis is compared in Fig. 4 with the present experimental data for temperatures of 52 and $132 \mathrm{~K}$. The theoretical predictions obtained for an RRHO treatment of the $\mathrm{CH}_{3} \mathrm{CN}$... CN state density (dotted lines) are more than two orders of magnitude too low. Replacing the RRHO state density with the anharmonic state density obtained from phase space sampling (the dashed line) yields an increase in the predicted rate coefficient by more than an order of magnitude. Nevertheless, the rate predictions still fall well below the experimental observations. As discussed in the theory section, there is great uncertainty in the proper treatment of energy transfer for a van der Waals complex at low temperature. The solid lines illustrate the theoretical results obtained when the Lennard-Jones radius of the van der Waals complex is 
used as a temperature independent fitting parameter. The optimized value of $28 \AA$ for this parameter is somewhat unrealistic, but it is probably worth emphasizing that at low temperatures very little energy transfer is required to result in stabilization. In that case, it is not clear what the proper collision radius should be, especially for a highly fluxional complex. In any case, we simply interpret the optimized parameter as accounting for the composite of errors in the energy transfer probabilities and collision rate (which cannot really be decoupled) and in the density of states for the complex. This level of uncertainty does not seem unrealistic. Notably, the study of Shannon et al. $2014^{65}$ instead employed a well depth that was $50 \%$ larger than that predicted by ab initio calculations as an alternative means to correct for too low a predicted stabilization rate.

From Fig. 4 it is clear that experiment and theory agree that the observable pressure window corresponds to the falloff regime, well away from both the high pressure limit and the tunneling dominated low pressure limit. The Eckart tunneling modeling is often inaccurate and can only be taken to provide semiquantitative estimates. However, even a factor of two increase in all of the imaginary frequencies (which correlates with an unreasonably large uncertainty in the tunneling integrals) does not affect the predicted rate coefficients in the experimentally observed pressure range at these temperatures. Similarly, reasonable revisions in barrier heights do not significantly affect the predicted rates for the experimentally observed temperatures and pressures. Instead, for the experimental conditions at $\mathrm{T}=52$ and $132 \mathrm{~K}$, the loss of $\mathrm{CN}$ is simply determined by the rate of formation and stabilization of the $\mathrm{CH}_{3} \mathrm{CN}$...CN complex.

In Fig. 5, the theoretically predicted rate coefficients for a wide range of temperature at a pressure of 2.5 mbar are compared with a select set of experimental data. The experimental data is the same set that was chosen for illustration in Fig. 2. The reference theoretical predictions (black dashed line) show much the same qualitative behavior as the experimental observations. The decrease in the rate coefficient with increasing temperature from low temperature to $180 \mathrm{~K}$ is due to the decreasing probability of stabilization. The sudden drop in the rate coefficient at $180 \mathrm{~K}$ is due to the lack of stability of the $\mathrm{CH}_{3} \mathrm{CN}$...CN complex at higher temperature. i.e., above $180 \mathrm{~K}$ the decomposition of the van der Waals complex occurs on the same timescale as collision induced vibrational energy relaxation. Then, from $200 \mathrm{~K}$ the predicted rate coefficient rises with increasing temperature, as the rates for the formation of the chemical complexes [ $\mathrm{NCC}\left(\mathrm{CH}_{3}\right) \mathrm{N}$ and $\mathrm{CH}_{3} \mathrm{CNCN}$ ] as well as for the abstraction to form $\mathrm{HCN}+$ $\mathrm{CH}_{2} \mathrm{CN}$ begin to become significant. Also, note that the experimental data at low temperature is for pressures below $1 \mathrm{mbar}$ and with He as a bath gas, whereas the theoretical calculations are for 2.5 mbar and Ar. The use of a lower pressure in the theoretical analysis would improve the comparison with experiment, but would not resolve the difference in the predicted temperature behavior for a given pressure. 
An increase in the collisional energy transfer rates (through the increase in the Lennard-Jones $\sigma$ for the van der Waals complex) increases the low temperature rate coefficients and increases the magnitude of the sudden drop at $180 \mathrm{~K}$ (red solid line). Both of these aspects are in accord with the experimental observations. One aspect of the experiment that remains difficult to interpret is the absence of any temperature dependence at low temperatures. According to theory, the rate coefficient should not become temperature independent until it reaches the capture rate, which is predicted to be $\sim 7.3 \times 10^{-10} \mathrm{~cm}^{3}$ molecule ${ }^{-1} \mathrm{~s}^{-1}$ for this system in the 20 to $300 \mathrm{~K}$ temperature range. In contrast, the experimental rate coefficient appears to become more or less temperature independent when it reaches $6 \times 10^{-11} \mathrm{~cm}^{3}$ molecule $\mathrm{s}^{-1} \mathrm{~s}^{-1}$. It is also difficult to reproduce the observed steepness of the drop in the rate coefficient at $130 \mathrm{~K}$. This difficulty may indicate that redissociation back to reactants of stabilized van der Waals complexes plays some role in the experimental observations.

At higher temperature the theoretical model somewhat underpredicts the observed rate coefficients (by a factor of two at room temperature). Interestingly, the present higher temperature experimental data lie between the variational (red solid) and non-variational results (light blue dotted). The minor discrepancies may thus simply be an indication of minor problems with the present variational RRKM analysis related to ambiguities in coordinate definitions for the proper evaluation of variational effects. Alternatively, the shortcomings may be indicative of the need to consider anharmonic effects for the tight transition states as well. Notably, although a lowering of all the barrier heights by just $0.2 \mathrm{kcal} / \mathrm{mol}$ (which is within the uncertainty of the present electronic structure analysis) yields room temperature rate predictions in quantitative agreement with the present experiments, the $350 \mathrm{~K}$ rate predictions then still lie significantly below experiment.

A more complete illustration of the theoretically predicted temperature and pressure dependence is provided in Fig. 6. From this plot we see that at higher pressure the predicted temperature pressure evolution more closely maps the experimentally observed pressure dependence than do the predictions for 2.5 mbar. This observation again suggests that the theory-experiment discrepancies may simply be indicative of shortcomings in the present simplistic treatment of the energy transfer process.

The role of the different chemical reaction channels in the kinetics is illustrated in Fig. 7, where the predicted individual channel rate coefficients are plotted versus temperature for a pressure of 0.5 mbar. The production of $\mathrm{NCC}\left(\mathrm{CH}_{3}\right) \mathrm{N}$ (and its dissociation product $\mathrm{NCCN}+\mathrm{CH}_{3}$ ) dominate the kinetics for temperatures below $700 \mathrm{~K}$ and lower. At higher temperatures the abstraction channels are increasingly important with the $\mathrm{HCN}+\mathrm{CH}_{2} \mathrm{CN}$ channel dominant above 700 . The $\mathrm{CH}_{3} \mathrm{CNCN}$ channel remains of minor significance at all temperatures. Interestingly, at very low 
temperature, the high barrier $\left(13 \mathrm{kcal} / \mathrm{mol}\right.$ ) abstraction to produce $\mathrm{HNC}+\mathrm{CH}_{2} \mathrm{CN}$ becomes significant due to a large imaginary frequency $\left(2500 \mathrm{~cm}^{-1}\right)$.

\subsection{Comparison with $\mathrm{OH}+$ acetone/Dimethyl Ether reactions}

The temperature evolution of the rate coefficient observed in the present work is qualitatively similar to that obtained in recent studies of the kinetics of the $\mathrm{OH}$ radical with oxygenated volatile organic compounds ${ }^{62-65}$ namely: methanol, acetone, methyl ethyl ketone MEK, dimethyl ether DME, ethanol, and propan-2-ol. Nevertheless, the reactive mechanisms were found to be different from each other. The $\mathrm{OH}+\mathrm{CH}_{3} \mathrm{OH}$ reaction was found to be pressure independent and tunneling was claimed to be the dominant process leading to formation of $\mathrm{CH}_{3} \mathrm{O}$ which was detected experimentally. ${ }^{64}$ Conversely, the rate coefficients for the reactions $\mathrm{OH}+\mathrm{CH}_{3} \mathrm{C}(\mathrm{O}) \mathrm{CH}_{3}$ and $\mathrm{CH}_{3} \mathrm{OCH}_{3}$ have been shown to be clearly pressure dependent at $80 \mathrm{~K}$ and more slightly at $140 \mathrm{~K}$. Extrapolations to zero pressure led to a positive intercept like in the present study. Analogous observations were made for the $\mathrm{OH}+\mathrm{CH}_{3} \mathrm{CH}_{2} \mathrm{OH}$ and $\mathrm{CH}_{3} \mathrm{CH}(\mathrm{OH}) \mathrm{CH}_{3}$ reactions.

The rate coefficients obtained for the reaction of $\mathrm{OH}$ with acetone were more comparable to the present work. On the one hand, indeed, the minimum of the rate coefficient was found to be $\sim 1-2 \times 10^{-13} \mathrm{~cm}^{3}$ molecule ${ }^{-1} \mathrm{~s}^{-1}$ at about $200 \mathrm{~K}$, and on the other hand, $k(T)$ was measured to be of the order of $5-10 \times 10^{-11} \mathrm{~cm}^{3}$ molecule $\mathrm{s}^{-1}$ around $80 \mathrm{~K} .{ }^{65}$ Both observations are quite similar to the data plotted in Fig. 1 from the present investigation. No data were reported at lower temperatures, however Shannon et al. were able to calculate the rate coefficients as a function of temperature and pressure and showed that both reactions proceed via two competing mechanisms: formation and collisional stabilization of a pre-reactive complex, which was favored at low temperatures, and tunneling. The latter contribution was found to be small with respect to the association process, being of the order of $10 \%$ of the collision rate. In the limit of zero pressure, however, the rate coefficient for the reaction $\mathrm{OH}+\mathrm{CH}_{3} \mathrm{C}(\mathrm{O}) \mathrm{CH}_{3}$, at $10 \mathrm{~K}$, was estimated to be $\sim 5 \times 10^{-11} \mathrm{~cm}^{3}$ molecule ${ }^{-1} \mathrm{~s}^{-1}$, a quite fast value of potential interstellar interest. In our work, contribution of tunneling was found to be much less significant with the association contribution mainly driving the reaction.

\section{Summary and Conclusions}

In the present paper a quite exhaustive study of the gas phase reactivity of the $\mathrm{CN}$ radical with acetonitrile has been described. The experimental behavior of the rate coefficient as a function of temperature and pressure is compatible with the presence of an activation barrier and a prereactive complex which can stabilize only at temperatures lower than $200 \mathrm{~K}$. These experiments demonstrate that the reactive mechanism changes from a classic Arrhenius 
process at high ( $>200 \mathrm{~K}$ ) temperatures to a three body mechanism at low temperatures. The more striking feature of the experimental data is certainly the increase by two orders of magnitude of the rate coefficients within only $45 \mathrm{~K}$.

The experimental conclusions have been confirmed and emphasized by detailed theoretical calculations which identified the reaction pathways on the one hand and determined the total and partial rate coefficients for the various possible exit channels on the other hand. The pressure dependences observed experimentally at 52 and $132 \mathrm{~K}$ are correctly matched by the theoretical analysis provided that an anharmonic state density is considered for the van der Waals complex $\mathrm{CH}_{3} \mathrm{CN}$...CN and its Lennard-Jones radius $\sigma$ is varied from $8 \AA$ to $28 \AA$ in order to adjust the effective energy transfer rates between the complex and the argon bath gas. Although this latter value can appear as somewhat unrealistic, it may reflect the combination of errors issued from the evaluation of the energy transfer probabilities and collision rates from one side and of the density of states for the van der Waals complex from another side. Additionally, calculations of the pressure dependence at 52 and $132 \mathrm{~K}$ clearly show that in the low pressure regime tunneling remains quite small $\left(<10^{-14} \mathrm{~cm}^{3}\right.$ molecule $\left.{ }^{-1} \mathrm{~s}^{-1}\right)$ and that experimental observations correspond to the falloff regime.

The dramatic experimental increase of the rate coefficient below $c a .180 \mathrm{~K}$ is qualitatively reproduced by the AITSTME approach although the weak temperature dependence observed below $123 \mathrm{~K}$ can only be mapped in the capture rate regime at pressures of about $100 \mathrm{mbar}$. This is a much higher value than those used in the experimental work ( $0.16-3.45 \mathrm{mbar})$. Furthermore, there is about one order of magnitude difference between the capture limit $(7.3 \mathrm{x}$ $10^{-10} \mathrm{~cm}^{3}$ molecule $\mathrm{s}^{-1}$ ) and the experimental asymptote at about $6 \times 10^{-11} \mathrm{~cm}^{3}$ molecule $\mathrm{s}^{-1}$ at $22 \mathrm{~K}$. These considerations may reflect that redissociation back to reactants of stabilized van der Waals complexes may occur in the experimental survey below $123 \mathrm{~K}$ and is also indicative of a possibly too simplistic treatment of the energy transfer process leading to stabilization of $\mathrm{CH}_{3} \mathrm{CN}$...CN.

Four chemical reaction channels have been identified in the kinetics calculations. Production of $\mathrm{NCC}\left(\mathrm{CH}_{3}\right) \mathrm{N}$, and its subsequent dissociation channel $\mathrm{NCCN}+\mathrm{CH}_{3}$, was found to dominate at $\mathrm{T}<$ $700 \mathrm{~K}$, whereas $\mathrm{HCN}+\mathrm{CH}_{2} \mathrm{CN}$ is the main channel at higher temperatures with an additional significant contribution of the other hydrogen abstraction route $\mathrm{HNC}+\mathrm{CH}_{2} \mathrm{CN}$.

From an astrochemical point of view, it is clear that the present studied reaction is not of interest for the interstellar medium because the bimolecular contribution of the total loss of CN has been found to be quite small below $100 \mathrm{~K}$. In addition, formation and stabilization of the van der Waals complex cannot be efficient as well in the very low pressure regime reigning in the interstellar medium. However, in the atmosphere of Titan, the pressure is much higher. For instance, at an altitude of about $100 \mathrm{~km}$, pressure is of the order of $10 \mathrm{mbar}$ and temperature is 
around $130 \mathrm{~K} .{ }^{94}$ In these conditions, from Fig. 4, it is possible to infer a rate coefficient of about $3 \times 10^{-11} \mathrm{~cm}^{3}$ molecule $\mathrm{s}^{-1}$ for the $\mathrm{CN}+\mathrm{CH}_{3} \mathrm{CN} \rightarrow \mathrm{CH}_{3} \mathrm{CN}$...CN reaction indicating that the van der Waals complex may be formed and survive in such an environment. Whereas abundance of $\mathrm{CH}_{3} \mathrm{CN}$ is rather small at this altitude (typ. $10^{-11}$ ), it significantly increases with altitude. ${ }^{3}$ For instance, at $300 \mathrm{~km}$, it is of the order of $10^{-8}$. In this situation however, the atmospheric pressure is about $0.1 \mathrm{mbar}$ and the temperature is around $180 \mathrm{~K}$ corresponding to the minimum of reactivity identified in the present work. As a consequence, even if the $\mathrm{CH}_{3} \mathrm{CN}$...CN can be formed rather efficiently in the Titan atmosphere, it will not have a significant effect on its chemistry.

\section{Acknowledgements}

Members of the Institute of Physics at Rennes and Laboratoire Univers et Particules de Montpellier are indebted to the French national program PCMI (Physique et Chimie du Milieu Interstellaire) for financial support. CS is grateful to the Conseil Régional de Bretagne for a three years fellowship and SGR acknowledges the "Ecole Doctorale" SDLM of the University of Rennes 1 for its financial participation during his three months stay in Rennes. DT acknowledges the HPC resources from GENCI-[CCRT/CINES/IDRIS] (grants 2015 [x2015085116] for computing time. Part of this material is based upon work at Argonne National Laboratory supported by the U.S. Department of Energy, Office of Science, Office of Basic Energy Sciences, Division of Chemical Sciences, Geosciences, and Biosciences under Contract No. DE-AC02-06CH11357. 
Table 1: Experimental conditions used in the CRESU apparatus for the determination of the $\mathrm{CN}+$ $\mathrm{CH}_{3} \mathrm{CN}$ rate coefficients.

\begin{tabular}{|c|c|c|c|c|c|c|}
\hline $\begin{array}{l}T^{a} \\
\mathrm{~K}\end{array}$ & $\begin{array}{c}\mathrm{n}_{\mathrm{tot}} \\
10^{16} \mathrm{~cm}^{-3}\end{array}$ & $\begin{array}{l}P_{c h} \\
\text { mbar }\end{array}$ & $\begin{array}{c}\text { Buffer } \\
\text { gas }\end{array}$ & $\begin{array}{c}{\left[\mathrm{CH}_{3} \mathrm{CN}\right]^{\mathrm{b}}} \\
10^{12} \mathrm{molec} \mathrm{cm}^{-3}\end{array}$ & $\begin{array}{c}\text { Number } \\
\text { of } \\
\text { measures }\end{array}$ & $\begin{array}{c}k^{c} \\
10^{-11} \mathrm{~cm}^{3} \mathrm{molec}^{-1} \mathrm{~s}^{-1}\end{array}$ \\
\hline $22.9 *$ & 4.73 & 0.165 & $\mathrm{He}$ & $29-321$ & 10 & $5.08 \pm 0.99$ \\
\hline $24.1 *$ & 18.3 & 0.63 & $\mathrm{He}$ & $42-350$ & 10 & $4.52 \pm 0.64$ \\
\hline $36.1 *$ & 5.28 & 0.293 & $\mathrm{He}$ & $22.3-163$ & 13 & $6.09 \pm 0.79$ \\
\hline $49.1 *$ & 10.4 & 0.77 & $\mathrm{He}$ & $74-447$ & 10 & $4.08 \pm 0.52$ \\
\hline${ }^{\#} 52.4$ & 3.48 & 0.248 & $\mathrm{Ar}$ & $9-63$ & $9 ; 9$ & $3.36 \pm 0.41$ \\
\hline${ }^{\#} 52.2$ & 5.15 & 0.39 & $\mathrm{Ar}$ & $9-148$ & $9 ; 9$ & $3.17 \pm 0.51$ \\
\hline${ }^{\#} 52.3 *$ & 10.3 & 0.782 & $\mathrm{Ar}$ & $15-106$ & 11 & $5.62 \pm 0.66$ \\
\hline${ }^{*} 52.8$ & 20.2 & 1.51 & Ar & $5-47$ & 8 & $8.95 \pm 1.06$ \\
\hline${ }^{*} 53.9$ & 40.1 & 3.04 & $\mathrm{Ar}$ & $2-22$ & 10 & $10.11 \pm 1.72$ \\
\hline${ }^{\#} 52.4$ & 82.1 & 5.97 & $\mathrm{Ar}$ & $2-21$ & 10 & $12.2 \pm 1.93$ \\
\hline $71.6^{*}$ & 6.01 & 0.64 & $\mathrm{He}$ & $43-500$ & 10 & $3.45 \pm 0.47$ \\
\hline $88.3 *$ & 27.4 & 3.45 & $\mathrm{He}$ & $191-822$ & 10 & $4.44 \pm 0.64$ \\
\hline $97.4^{*}$ & 15.4 & 2.16 & $\mathrm{Ar}$ & $45-197$ & 10 & $4.79 \pm 0.64$ \\
\hline $123^{*}$ & 12.7 & 2.28 & $\mathrm{He}$ & $35-147$ & 9 & $2.62 \pm 1.23$ \\
\hline${ }^{\#} 132.9$ & 3.39 & 0.62 & $\mathrm{Ar}$ & $371-1175$ & 12 & $0.37 \pm 0.04$ \\
\hline${ }^{\#} 132.9$ & 8.2 & 1.55 & $\mathrm{Ar}$ & $106-1146$ & 10 & $0.62 \pm 0.08$ \\
\hline${ }^{\#} 131.3 *$ & 12.4 & 2.3 & $\mathrm{Ar}$ & $48-526$ & 9 & $0.83 \pm 0.08$ \\
\hline${ }^{\#} 132.7$ & 16.5 & 3.15 & Ar & $186-1201$ & 8 & $1.03 \pm 0.12$ \\
\hline $136.2 *$ & 11.9 & 2.36 & $\mathrm{Ar}$ & $633-2394$ & 9 & $0.52 \pm 0.09$ \\
\hline $141.1 *$ & 6.95 & 1.45 & Ar & $615-2796$ & 10 & $0.15 \pm 0.02$ \\
\hline $152.1 *$ & 7.72 & 1.66 & Ar & $1328-6058$ & 10 & $0.039 \pm 0.006$ \\
\hline $168.0 *$ & 9.01 & 2.17 & $\mathrm{Ar}$ & $1448-7189$ & 9 & $0.020 \pm 0.005$ \\
\hline $297 *$ & 11.8 & 4.84 & $\mathrm{Ar}$ & $2075-7541$ & 5 & $0.029 \pm 0.006$ \\
\hline $297 *$ & 63.6 & 26.1 & $\mathrm{Ar}$ & $369-2680$ & 7 & $0.031 \pm 0.008$ \\
\hline
\end{tabular}

a*: data plotted in Fig. 1 ; \# data plotted in Fig. 2.

${ }^{b}$ The range of acetonitrile concentrations.

${ }^{\mathrm{C}}$ Errors are a combination of statistical and systematic errors (see text). 
Table 2: Experimental conditions used in the cryocell reactor for the determination of the $\mathrm{CN}+$ $\mathrm{CH}_{3} \mathrm{CN}$ rate coefficients. ${ }^{a}$

\begin{tabular}{ccccccc}
\hline $\mathrm{T}$ & $\begin{array}{c}\mathrm{n}_{\text {tot }} \\
\mathrm{K}\end{array}$ & $\begin{array}{c}P_{\text {Cryocell }}{ }^{17} \text { molec } \mathrm{cm}^{-3} \\
\text { mbar }\end{array}$ & $\begin{array}{c}\text { Buffer } \\
\text { Gas }\end{array}$ & $\begin{array}{c}{\left[\mathrm{CH}_{3} \mathrm{CN}\right]^{\mathrm{b}}} \\
10^{12} \text { molec } \mathrm{cm}^{-3}\end{array}$ & $\begin{array}{c}\text { Number } \\
\text { of } \\
\text { measures }\end{array}$ & $\begin{array}{c}k^{c} \\
10^{-13} \mathrm{~cm}^{3} \mathrm{molec}^{-1} \mathrm{~s}^{-1}\end{array}$ \\
\hline 258 & 7.06 & 25.2 & $\mathrm{Ar}$ & $1832-48362$ & 9 & $1.96 \pm 0.33$ \\
297 & 6.62 & 27.1 & $\mathrm{Ar}$ & $619-6627$ & 11 & $2.78 \pm 0.33$ \\
297 & 19.70 & 80.8 & $\mathrm{Ar}$ & $321-8746$ & 9 & $2.93 \pm 0.54$ \\
297 & 6.45 & 26.5 & $\mathrm{He}$ & $188-2542$ & 8 & $2.61 \pm 0.69$ \\
354 & 5.85 & 28.6 & $\mathrm{Ar}$ & $55-4356$ & 14 & $9.31 \pm 1.43$ \\
\hline
\end{tabular}

${ }^{a}$ All data are plotted in Fig. 1 with a weighted mean value for $297 \mathrm{~K}$.

${ }^{b}$ The range of acetonitrile concentrations.

${ }^{\mathrm{c}}$ Errors are a combination of statistical and systematic errors (see text). 
Table 3: Stationary point energies for the $\mathrm{CN}+\mathrm{CH}_{3} \mathrm{CN}$ system. ${ }^{a}$

\begin{tabular}{|c|c|c|c|c|}
\hline Stationary Point & Label $^{b}$ & $\mathrm{G} 4^{\mathrm{c}}$ & $\mathrm{HL}^{\mathrm{d}}$ & $\mathrm{T} 1^{\mathrm{e}}$ \\
\hline $\mathrm{CN}+\mathrm{CH}_{3} \mathrm{CN}$ & $\mathrm{R}$ & 0 & 0 & $0.052,0.013$ \\
\hline $\mathrm{NCC}\left(\mathrm{CH}_{3}\right) \mathrm{N}$ & W1 & -36.9 & -34.76 & 0.016 \\
\hline $\mathrm{CH}_{3} \mathrm{CNCN}$ & W2 & -21.3 & -19.3 & 0.022 \\
\hline $\mathrm{NC} . . . \mathrm{CH}_{3} \mathrm{CN}$ & vdW1 & -2.37 & $\begin{array}{c}-0.97 \\
-1.13^{f}\end{array}$ & 0.029 \\
\hline $\mathrm{CH}_{3} \mathrm{CN}$...CN; linear & $\mathrm{vdW} 2$ & -3.45 & $\begin{array}{c}-2.47 \\
-2.72^{f}\end{array}$ & 0.029 \\
\hline $\mathrm{CH}_{3} \mathrm{CN}$...CN; bent & vdW3 & -2.79 & $-2.54^{f}$ & 0.029 \\
\hline $\mathrm{CH}_{3} \mathrm{CN}+\mathrm{CN}=\mathrm{CH}_{2} \mathrm{CN}+\mathrm{HCN}$ & TS1 & -0.30 & 3.19 & 0.025 \\
\hline $\mathrm{CH}_{3} \mathrm{CN}+\mathrm{CN}=\mathrm{CH}_{2} \mathrm{CN}+\mathrm{HNC}$ & TS2 & 12.1 & 12.86 & 0.054 \\
\hline $\mathrm{CH}_{3} \mathrm{CN} \ldots \mathrm{CN}=\mathrm{NCC}\left(\mathrm{CH}_{3}\right) \mathrm{N}$ & TS3 & -0.33 & 1.44 & 0.023 \\
\hline $\mathrm{CH}_{3} \mathrm{CN} \ldots \mathrm{CN}=\mathrm{CH}_{3} \mathrm{CNCN}$ & TS4 & 0.21 & 2.50 & 0.019 \\
\hline $\mathrm{NCC}\left(\mathrm{CH}_{3}\right) \mathrm{N}=\mathrm{CH}_{3}+\mathrm{NCCN}$ & TS5 & -7.00 & -6.04 & 0.019 \\
\hline $\mathrm{CH}_{3}+\mathrm{NCCN}$ & P1 & -16.4 & -14.1 & $0.006,0.015$ \\
\hline $\mathrm{CH}_{2} \mathrm{CN}+\mathrm{HCN}$ & P2 & -31.0 & -29.3 & $0.023,0.015$ \\
\hline $\mathrm{CH}_{2} \mathrm{CN}+\mathrm{HNC}$ & P3 & -16.2 & -14.3 & $0.023,0.017$ \\
\hline $\mathrm{CH}_{3}+\mathrm{CNCN}$ & P4 & 8.2 & 11.2 & $0.006,0.018$ \\
\hline
\end{tabular}

${ }^{a}$ All energies include ZPE correction and are relative to $\mathrm{CN}+\mathrm{CH}_{3} \mathrm{CN}$.

${ }^{\mathrm{b}} \mathrm{R}$ : reactants; W: well; vdW: van der Waals; TS: transition state; P: products

${ }^{\mathrm{c}}$ Present G4 predictions.

${ }^{\mathrm{d}}$ Present high level predictions.

${ }^{\mathrm{e}} \mathrm{T} 1$ diagnostic for present $\mathrm{CCSD}(\mathrm{T}) /$ aug'-cc-pV5Z calculations.

${ }^{f}$ The numbers in bold italics are for the rovibrational analysis performed at the CCSD(T)-F12/cCpVDZ-F12 level. 


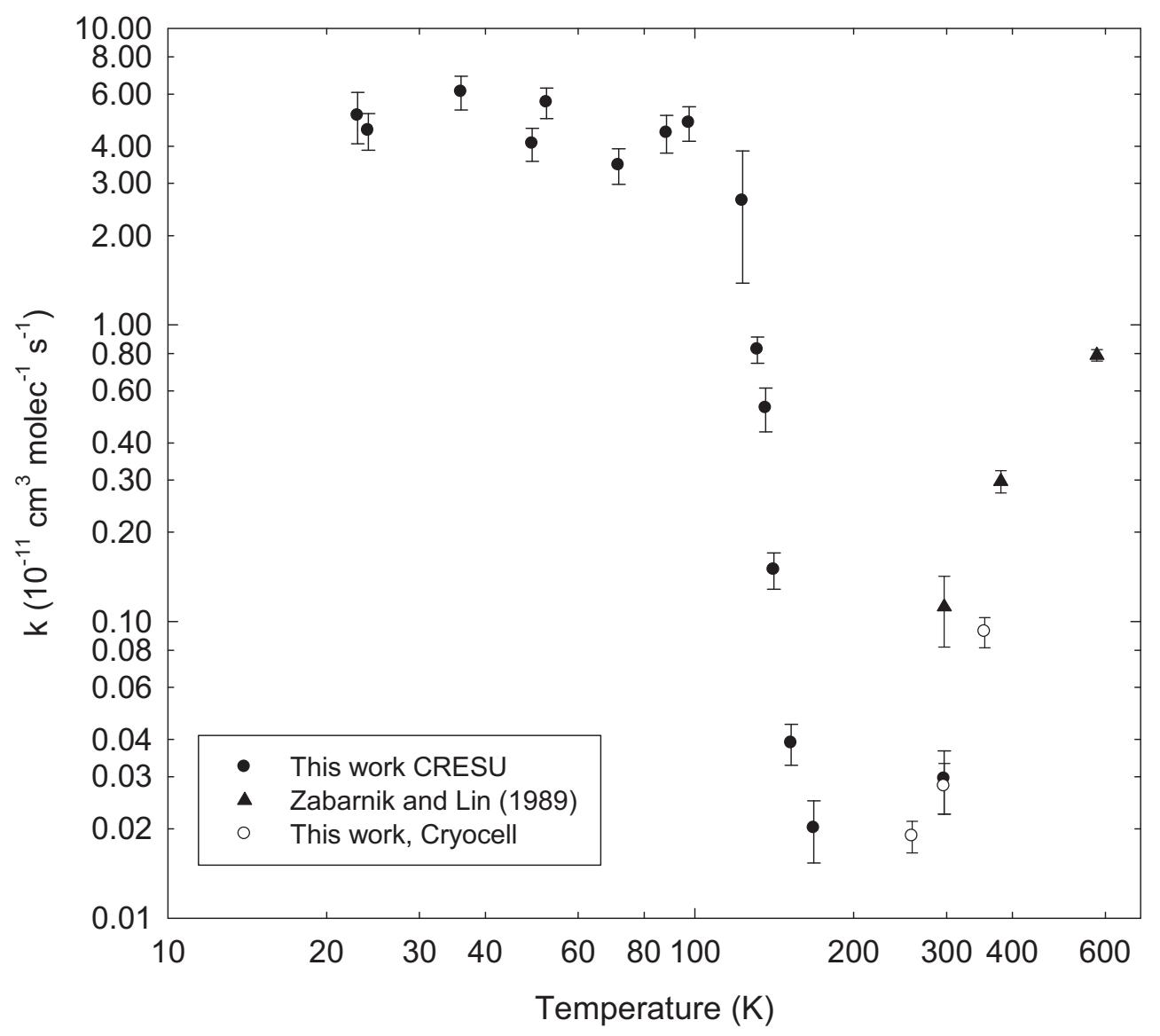

Fig. 1: Rate coefficient plotted as a function of temperature. Error bars are a combination of statistical and systematic errors (see text). 


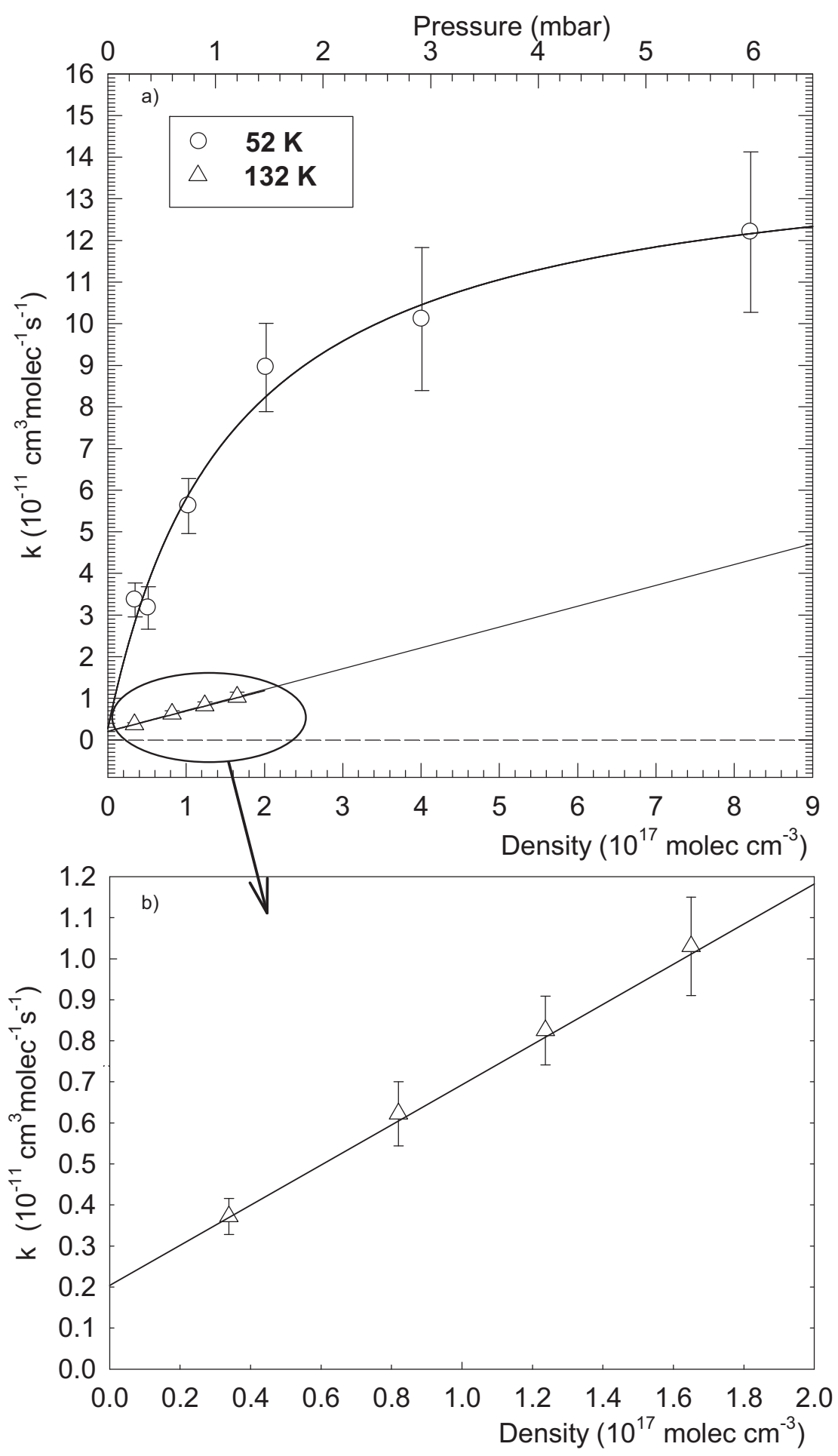

Fig. 2: Rate coefficient as a function of the total density for two temperatures: $52 \mathrm{~K}$ and $132 \mathrm{~K}$ in a) and $132 \mathrm{~K}$ in b). 


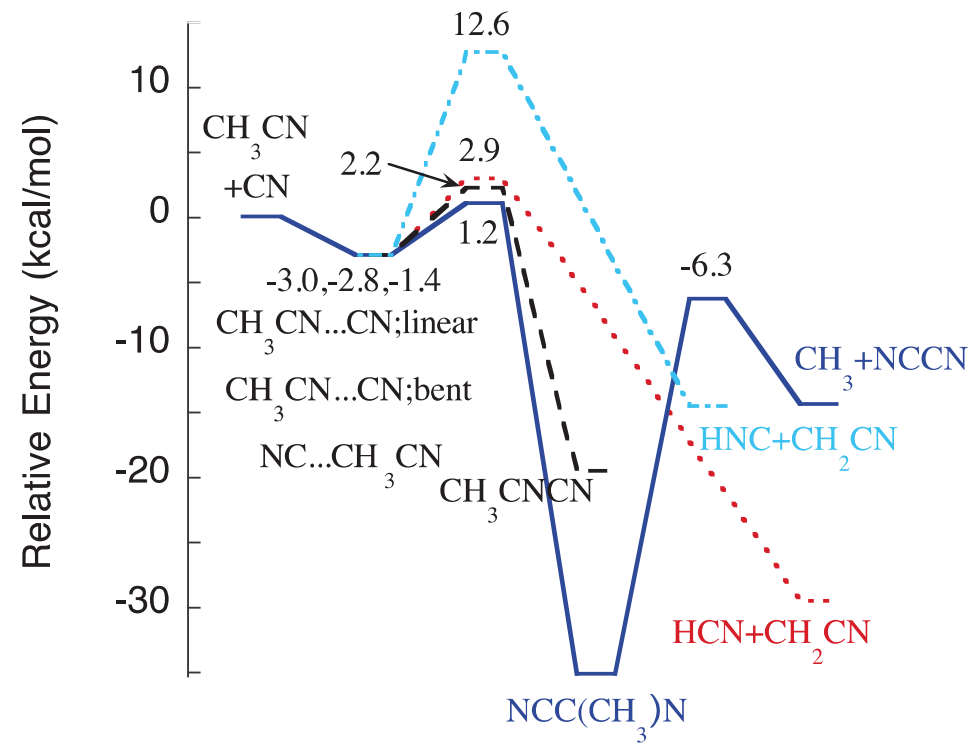

Fig. 3: Schematic plot of the reaction pathways for the interaction of $\mathrm{CN}$ with $\mathrm{CH}_{3} \mathrm{CN}$. The numbers denote the present $\mathrm{HL}$ results for the zero-point corrected energies in $\mathrm{kcal} / \mathrm{mol}$, and include a $0.26 \mathrm{kcal} / \mathrm{mol}$ adjustment in the energy of $\mathrm{CN}$ (see text). 


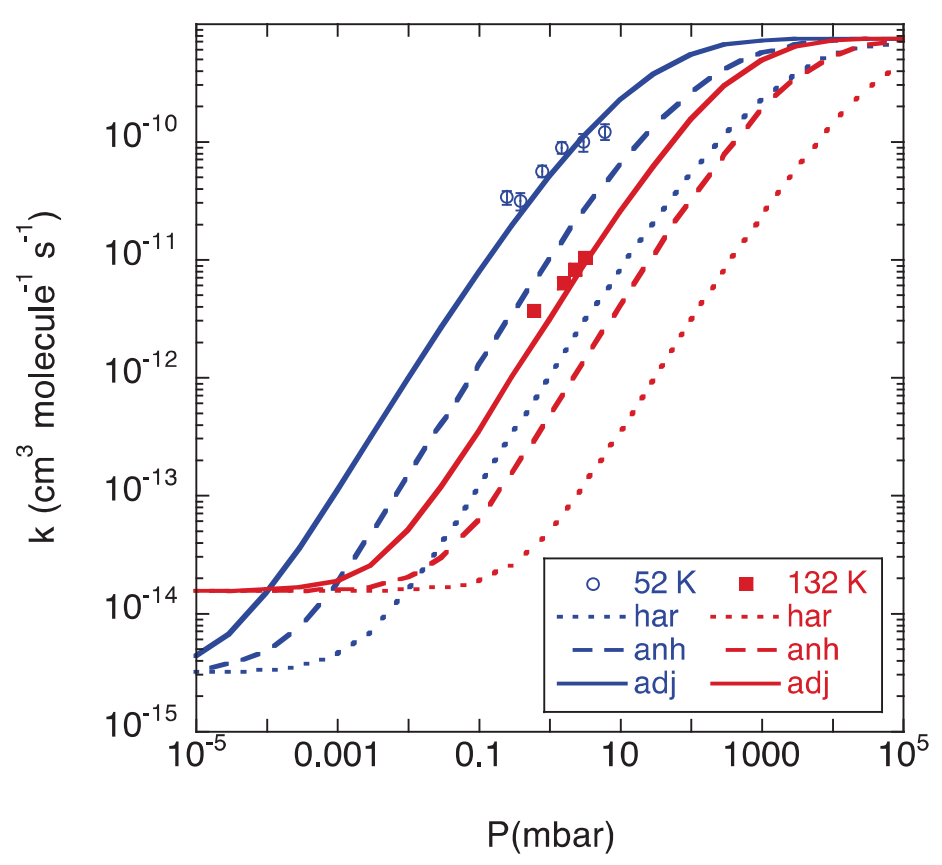

Fig. 4: Plot of the predicted pressure dependence of the $C N$ loss rate coefficient at $T=52$ and $132 \mathrm{~K}$. The symbols denote experimental results, while the lines denote various theoretical predictions (har: harmonic, anh: anharmonic, adj: adjusted). The dotted line employs an RRHO based density of states, the dashed and solid lines employ the anharmonic-phase space integral determined density of states, with the latter calculation adjusted to agree with experiment by employing an artificial Lennard Jones $\sigma$ value of $28 \AA$. 


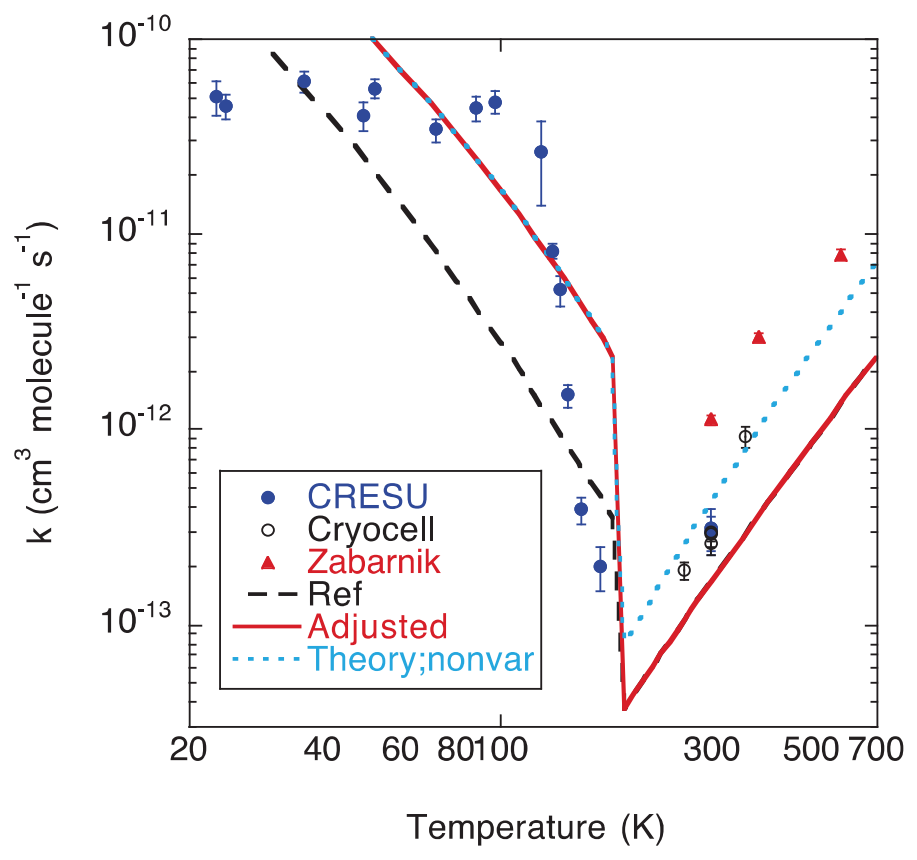

Fig. 5: Temperature dependence of the rate coefficient. The experimental values (symbols) are as in Fig. 1. The theoretical values (lines) are for a pressure of 2.5 mbar. The black dashed line denotes the reference theoretical model, the red solid line denotes the model with a revised bath gas collision rate (as in Fig. 4), and the blue dotted line denotes the neglect of variational effects for the tight transition states in the revised model. 




Fig. 6: Calculated rate coefficient as a function of temperature and pressure (in mbar) for the adjusted theoretical model. 


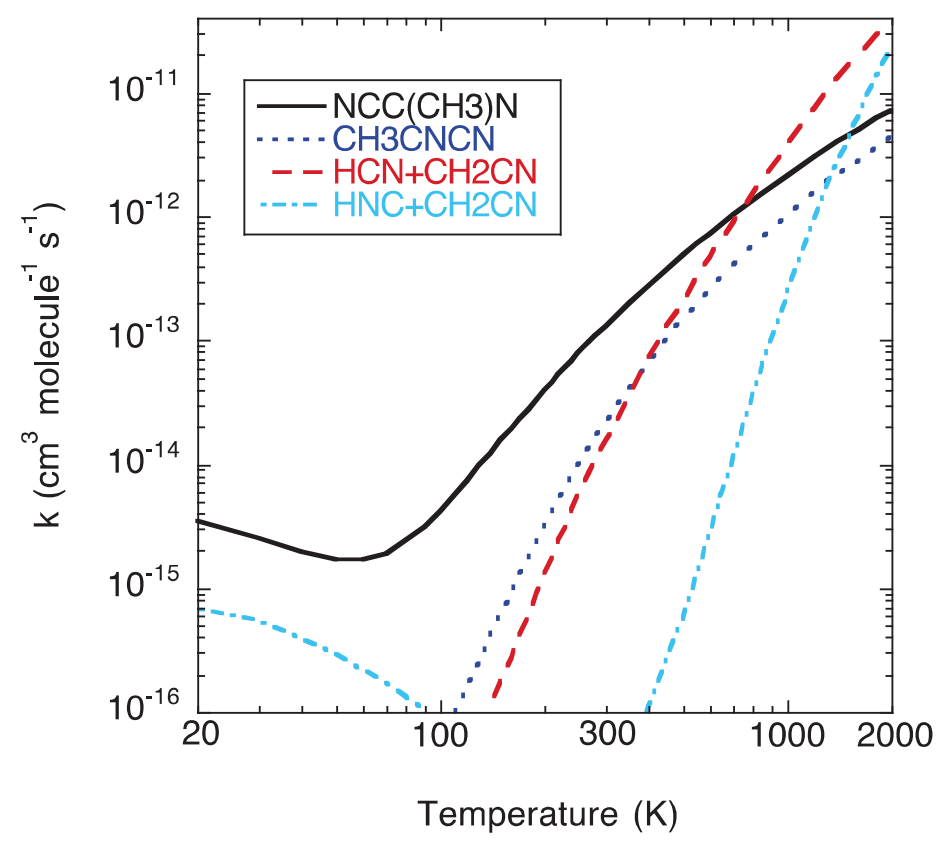

Fig. 7: Channel specific calculated rate coefficients as a function of temperature for a pressure of 0.5 mbar. 


\section{References}

1 Q. B. Li, D. J. Jacob, R. M. Yantosca, C. L. Heald, H. B. Singh, M. Koike, Y. J. Zhao, G. W. Sachse, and D. G. Streets, A global three-dimensional model analysis of the atmospheric budgets of $\mathrm{HCN}$ and $\mathrm{CH}_{3} \mathrm{CN}$ : Constraints from aircraft and ground measurements, $J$. Geophys. Res. - Atm., 2003, 108, 8827.

2 J. J. Harrison and P. F. Bernath, ACE-FTS observations of acetonitrile in the lower stratosphere, Atm. Chem. Phys., 2013, 13, 7405.

3 A. Marten, T. Hidayat, Y. Biraud, and R. Moreno, New millimeter heterodyne observations of Titan: Vertical distributions of nitriles $\mathrm{HCN}, \mathrm{HC}_{3} \mathrm{~N}, \mathrm{CH}_{3} \mathrm{CN}$, and the isotopic ratio $\mathrm{N}-15 / \mathrm{N}-14$ in its atmosphere, Icarus, 2002, 158, 532.

4 V. Vuitton, R. V. Yelle, and M. J. McEwan, lon chemistry and N-containing molecules in Titan's upper atmosphere, Icarus, 2007, 191, 722.

5 N. Biver, M. D. Bockelee, J. Crovisier, P. Colom, F. Henry, R. Moreno, G. Paubert, D. Despois, and D. C. Lis, Chemical Composition Diversity among 24 Comets observed at Radio Wavelengths, Earth Moon Plan., 2002, 90, 323.

6 B. L. Ulich and E. K. Conklin, Detection of methyl cyanide in comet-Kohoutek, Nature, 1974, 248, 121.

7 D. J. Wilner, M. C. H. Wright, and R. L. Plambeck, Maps of 92 Ghz methyl cyanide emission in Orion-KI, Astrophys. J., 1994, 422, 642.

8 P. M. Solomon, K. B. Jefferts, A. A. Penzias, and R. W. Wilson, Detection of millimeter emission lines from interstellar methyl cyanide, Astrophys. J., 1971, 168, L107.

9 H. E. Matthews and T. J. Sears, Detection of the $\mathrm{J}=1->0$ transition of $\mathrm{CH}_{3} \mathrm{CN}$, Astrophys. J., 1983, 267, L53-L57.

10 M. Guelin and J. Cernicharo, Astronomical detection of the HCCN radical - Toward a new family of carbon-chain molecules, Astron. Astrophys., 1991, 244, L21-L24. 
11 P. Gratier, J. Pety, V. Guzman, M. Gerin, J. R. Goicoechea, E. Roueff, and A. Faure, The IRAM-30 $\mathrm{m}$ line survey of the Horsehead PDR III. High abundance of complex (iso-)nitrile molecules in UV-illuminated gas, Astron. Astrophys., 2013, 557, A101.

12 L. Olmi, R. Cesaroni, and C. M. Walmsley, Ammonia and methyl cyanide in hot cores, Astron. Astrophys., 1993, 276, 489.

13 V. Pankonin, E. Churchwell, C. Watson, and J. H. Bieging, A methyl cyanide search for the earliest stages of massive protostars, Astrophys. J., 2001, 558, 194.

14 V. Bujarrabal, J. Gomez-Gonzalez, R. Bachiller, and J. Martin-Pintado, Proto-planetary nebulae - the case of CRL-618, Astron. Astrophys., 1988, 204, 242.

15 H. G. Arce, J. Santiago-Garcia, J. K. Jorgensen, M. Tafalla, and R. Bachiller, Complex molecules in the L1157 molecular outflow, Astrophys. J. Lett, 2008, 681, L21-L24.

16 R. Mauersberger, C. Henkel, C. M. Walmsley, L. J. Sage, and T. Wiklind, Dense gas in nearby galaxies .5. Multilevel studies of $\mathrm{CH}_{3} \mathrm{CCH}$ and $\mathrm{CH}_{3} \mathrm{CN}$, Astron. Astrophys., 1991, 247, 307.

17 G. Danger, J. B. Bossa, P. de Marcellus, F. Borget, F. Duvernay, P. Theule, T. Chiavassa, and L. d'Hendecourt, Experimental investigation of nitrile formation from VUV photochemistry of interstellar ices analogs: acetonitrile and amino acetonitrile, Astron. Astrophys., 2011, 525, A30.

18 G. W. Harris, T. E. Kleindienst, and J. N. Pitts, Rate constants for the reaction of $\mathrm{OH}$ radicals with $\mathrm{CH}_{3} \mathrm{CN}, \mathrm{C}_{2} \mathrm{H}_{5} \mathrm{CN}$ and $\mathrm{CH}_{2}=\mathrm{CH}-\mathrm{CN}$ in the temperature-range $298-424 \mathrm{~K}$, Chem. Phys. Lett., 1981, 80, 479.

19 M. J. Kurylo and G. L. Knable, A Kinetics Investigation of the Gas-Phase Reactions of $\mathrm{Cl}\left({ }^{2} \mathrm{P}\right)$ and $\mathrm{OH}\left(\mathrm{X}^{2} \Pi\right)$ with $\mathrm{CH}_{3} \mathrm{CN}$ - Atmospheric Significance and Evidence for Decreased Reactivity Between Strong Electrophiles, J. Phys. Chem., 1984, 88, 3305.

20 G. Poulet, G. Laverdet, J. L. Jourdain, and G. LeBras, Kinetic-study of the reactions of acetonitrile with $\mathrm{Cl}$ and $\mathrm{OH}$ Radicals, J. Phys. Chem., 1984, 88, 6259.

21 A. J. Hynes and P. H. Wine, Kinetics and Mechanism of the Reaction of Hydroxyl Radicals with Acetonitrile Under Atmospheric Conditions, J. Phys. Chem., 1991, 95, 1232.

22 G. S. Tyndall, J. J. Orlando, T. J. Wallington, and M. D. Hurley, Products of the chlorineatom- and hydroxyl-radical-initiated oxidation of $\mathrm{CH}_{3} \mathrm{CN}$, J. Phys. Chem. A, 2001, 105, 5380 .

23 W. B. DeMore, Regularities in Arrhenius parameters for rate constants of abstraction reactions of hydroxyl radical with C-H bonds, J. Photochem. Photobiol. A, 2005, 176, 129. 
24 Q. S. Li and C. Y. Wang, Direct dynamic study on the hydrogen abstraction reaction $\mathrm{CH}_{3} \mathrm{CN}+\mathrm{OH}->\mathrm{CH}_{2} \mathrm{CN}+\mathrm{H}_{2} \mathrm{O}$, J. Comput. Chem., 2004, 25, 251.

25 A. Galano, Mechanism of $\mathrm{OH}$ radical reactions with $\mathrm{HCN}$ and $\mathrm{CH}_{3} \mathrm{CN}$ : $\mathrm{OH}$ regeneration in the presence of $\mathrm{O}_{2}$, J. Phys. Chem. A, 2007, 111, 5086.

26 Y. Tian, T. He, D. Chen, and F. Liu, Reaction mechanism and kinetics for the reaction of $\mathrm{OH}+\mathrm{CH}_{3} \mathrm{CN}$, Act. Phys. Chim. Sin., 2008, 24, 587.

27 J. Olbregts, G. Brasseur, and E. Arijs, Reaction of Acetonitrile and Chlorine Atoms, J. Photochem., 1984, 24, 315.

28 K. M. Pei and H. Y. Li, Direct ab initio dynamics studies of hydrogen abstraction reaction: $\mathrm{Cl}+\mathrm{CH}_{3} \mathrm{CN}->\mathrm{HCl}+\mathrm{CH}_{2} \mathrm{CN}$, J. Mol. Struc. Theochem., 2004, 677, 67.

29 G. S. Tyndall, J. J. Orlando, T. J. Wallington, J. Sehested, and O. J. Nielsen, Kinetics of the reactions of acetonitrile with chlorine and fluorine atoms, J. Phys. Chem., 1996, 100, 660.

30 Q. S. Li and C. Y. Wang, A theoretical study on the two reactions of acetonitrile with atomic chlorine and bromine, J. Phys. Chem. A, 2002, 106, 8883.

31 C. A. Cantrell, J. A. Davidson, R. E. Shetter, B. A. Anderson, and J. G. Calvert, Reactions of $\mathrm{NO}_{3}$ and $\mathrm{N}_{2} \mathrm{O}_{5}$ with molecular-species of possible atmospheric Interest, J. Phys. Chem., 1987, 91, 6017.

32 E. Arijs and G. Brasseur, Acetonitrile in the stratosphere and implications for positive-ion composition, J. Geophys. Res. - Atm., 1986, 91, 4003.

33 R. J. Bonanno, R. B. Timmons, L. J. Stief, and R. B. Klemm, Kinetics and mechanisms of reactions of $\mathrm{O}\left({ }^{3} \mathrm{P}\right)$ atoms with $\mathrm{CH}_{3} \mathrm{CN}$ and $\mathrm{CF}_{3} \mathrm{CN}$, J. Chem. Phys., 1977, 66, 92.

34 S. Budge and J. M. Roscoe, The Reactions of $O\left({ }^{3} \mathrm{P}\right)$ with Acetonitrile and Propionitrile, Can. J. Chem., 1995, 73, 666.

35 J. Y. Sun, Y. Z. Tang, X. J. Jia, F. Wang, H. Sun, J. D. Feng, X. M. Pan, L. Z. Hao, and R. S. Wang, Theoretical study for the reaction of $\mathrm{CH}_{3} \mathrm{CN}$ with $\mathrm{O}\left({ }^{3} \mathrm{P}\right)$, J. Chem. Phys., 2010, 132, 64301.

36 R. S. Strekowski, J. M. Nicovich, and P. H. Wine, Kinetic and mechanistic study of the reactions of $\mathrm{O}\left({ }^{1} \mathrm{D}_{2}\right)$ with $\mathrm{HCN}$ and $\mathrm{CH}_{3} \mathrm{CN}$, Chemphyschem, 2010, 11, 3942.

$37 \mathrm{H}$. Schlager and F. Arnold, Balloon borne fragment ion mass-spectrometry studies of stratospheric positive-ions - Unambiguous detection of $\mathrm{H}^{+}\left(\mathrm{CH}_{3} \mathrm{CN}\right)_{1}\left(\mathrm{H}_{2} \mathrm{O}\right)_{\mathrm{m}}$-clusters, Planet. Spac. Sc., 1985, 33, 1363. 
38 E. Arijs, stratospheric ion chemistry - present understanding and outstanding problems, Planet. Spac. Sc., 1992, 40, 255.

39 D. Smith, N. G. Adams, and E. Alge, Ion-ion mutual neutralization and ion-neutral switching reactions of some stratospheric ions, Planet. Spac. Sc., 1981, 29, 449.

40 A. A. Viggiano, F. Dale, and J. F. Paulson, Proton-transfer reactions of $\mathrm{H}^{+}\left(\mathrm{H}_{2} \mathrm{O}\right)_{\mathrm{n}=2-11}$ with methanol, ammonia, pyridine, acetonitrile, and acetone, J. Chem. Phys., 1988, 88, 2469.

41 Y. L. Yung, M. Allen, and J. P. Pinto, Photochemistry of the atmosphere of Titan comparison between model and observations, Astrophys. J. Suppl. Ser., 1984, 55, 465.

42 J. C. Loison, E. Hebrard, M. Dobrijevic, K. M. Hickson, F. Caralp, V. Hue, G. Gronoff, O. Venot, and Y. Benilan, The neutral photochemistry of nitriles, amines and imines in the atmosphere of Titan, Icarus, 2015, 247, 218.

43 E. Hebrard, M. Dobrijevic, J. C. Loison, A. Bergeat, K. M. Hickson, and F. Caralp, Photochemistry of $\mathrm{C}_{3} \mathrm{H}_{\mathrm{p}}$ hydrocarbons in Titan's stratosphere revisited, Astron. Astrophys., 2013, 552, A132.

44 J. W. Jamieson, G. R. Brown, and J. S. Tanner, Reaction of atomic hydrogen with methyl cyanide, Can. J. Chem., 1970, 48, 3619.

45 B. S. Wang, H. Hou, and Y. S. Gu, Theoretical study of the reaction of atomic hydrogen with acetonitrile, J. Phys. Chem. A, 2001, 105, 156.

46 X. M. Zhou, X. L. Cheng, Y. Y. Zhao, and X. J. Tao, Accurate vibrational spectra and reaction mechanism of the reaction of atomic hydrogen with acetonitrile, J. Mol. Struc. Theochem., 2006, 763, 123.

47 R. J. Hoobler and S. R. Leone, Rate coefficients for reactions of ethynyl radical $\left(\mathrm{C}_{2} \mathrm{H}\right)$ with $\mathrm{HCN}$ and $\mathrm{CH}_{3} \mathrm{CN}$ : Implications for the formation of complex nitriles on Titan, J. Geophys. Res. Planet., 1997, 102, 28717.

48 B. Nizamov and S. R. Leone, Kinetics of $\mathrm{C}_{2} \mathrm{H}$ reactions with hydrocarbons and nitriles in the 104-296 K temperature range, J. Phys. Chem. A, 11-3-2004, 108, 1746.

49 J. Y. Sun, Y. Z. Tang, H. Sun, X. J. Jia, X. M. Pan, Y. R. Pan, and R. S. Wang, Theoretical study of the reaction of ethynyl radical with acetonitrile, Theor. Chem. Acc., 2008, 121, 33.

50 S. Zabarnick and M. C. Lin, Kinetics of $\mathrm{CN}\left(\mathrm{X}^{2} \Sigma^{+}\right)$Radical Reactions with $\mathrm{HCN}, \mathrm{BrCN}$ and $\mathrm{CH}_{3} \mathrm{CN}$, Chem. Phys., 1989, 134, 185.

51 V. A. Krasnopolsky, Chemical composition of Titan's atmosphere and ionosphere: Observations and the photochemical model, Icarus, 2014, 236, 83. 
52 D. McElroy, C. Walsh, A. J. Markwick, M. A. Cordiner, K. Smith, and T. J. Millar, The UMIST database for astrochemistry 2012, Astron. Astrophys., 2013, 550, A36.

53 D. D. S. MacKay, $\mathrm{CH}_{3} \mathrm{CN}$ photochemistry at hot core margins, Mon. Notic. Roy. Astron. Soc., 1999, 304, 61.

54 K. Willacy, D. A. Williams, and Y. C. Minh, Gas grain interactions and the E/A ratio of methyl cyanide in TMC-1, Mon. Notic. Roy. Astron. Soc., 1993, 263, L40-L42.

55 A. Belloche, R. Garrod, H. Mueller, K. Menten, C. Comito, and P. Schilke, Increased complexity in interstellar chemistry: detection and chemical modeling of ethyl formate and n-propyl cyanide in Sagittarius B2(N), Astron. Astrophys., 2009, 499, 215.

56 K. Hoyermann and J. Seeba, Mechanism and Rate of the Reaction of Cyanomethyl Radicals with Oxygen-Atoms in the Gas-Phase, Z. Phys. Chem - Int. J. Res. Phys. Chem. Chem. Phys., 1995, 188, 215.

57 D. J. Smith, D. W. Setser, K. C. Kim, and D. J. Bogan, HF IR chemiluminescence - relative rate constants for hydrogen abstraction from hydrocarbons, substituted methanes, and inorganic hydrides, J. Phys. Chem., 1977, 81, 898.

58 K. M. Pei and H. Y. Li, Direct ab initio dynamics studies of hydrogen abstraction reaction: $\mathrm{F}+\mathrm{CH}_{3} \mathrm{CN}->\mathrm{HF}+\mathrm{CH}_{2} \mathrm{CN}$, J. Mol. Struc. Theochem., 2004, 676, 105.

59 W. Forst, H. G. V. Evans, and C. A. Winkler, The kinetics of nitrogen atom reactions accompanied by catalyzed recombination of atoms, J. Phys. Chem., 1957, 61, 320.

$60 \mathrm{M}$. H. J. Wijnen, The reaction of methyl radicals with aceto-nitrile and propio-nitrile, J. Chem. Phys., 1954, 22, 1074.

61 S. P. Li and W. Y. Fan, FTIR and computational studies of gas-phase hydrogen atom abstraction kinetics by t-butoxy radical, Chem. Phys. Lett., 2006, 427, 276.

62 R. L. Caravan, R. J. Shannon, T. Lewis, M. A. Blitz, and D. E. Heard, Measurements of rate coefficients for reactions of $\mathrm{OH}$ with ethanol and propan-2-ol at very low temperatures, J. Phys. Chem. A, 2015, 119, 7130.

63 R. J. Shannon, S. Taylor, A. Goddard, M. A. Blitz, and D. E. Heard, Observation of a large negative temperature dependence for rate coefficients of reactions of $\mathrm{OH}$ with oxygenated volatile organic compounds studied at 86-112 K, Phys. Chem. Chem. Phys., 2010, 12, 13511.

64 R. J. Shannon, M. A. Blitz, A. Goddard, and D. E. Heard, Accelerated chemistry in the reaction between the hydroxyl radical and methanol at interstellar temperatures facilitated by tunnelling, Nat. Chem., 2013, 5, 745. 
65 R. J. Shannon, R. L. Caravan, M. A. Blitz, and D. E. Heard, A combined experimental and theoretical study of reactions between the hydroxyl radical and oxygenated hydrocarbons relevant to astrochemical environments, Phys. Chem. Chem. Phys., 2014, 16, 3466.

66 A. Canosa, F. Goulay, I.R. Sims, and B.R. Rowe in Low Temperatures and Cold Molecules, Ed.I.W.M.Smith, 2008, 55-120, Imperial College Press, London, UK.

67 G. Dupeyrat, J. B. Marquette, and B. R. Rowe, Design and testing of axisymmetric nozzles for ion molecule reaction studies between $20 \mathrm{~K}$ and $160 \mathrm{k}$, Phys. Fl., 1985, 28, 1273.

68 I. R. Sims, J. L. Queffelec, A. Defrance, C. Rebrion-Rowe, D. Travers, P. Bocherel, B. R. Rowe, and I. W. M. Smith, Ultra-low temperature kinetics of neutral-neutral reactions : The technique, and results for the reactions $\mathrm{CN}+\mathrm{O}_{2}$ down to $13 \mathrm{~K}$ and $\mathrm{CN}+\mathrm{NH}_{3}$ down to 25 K., J. Chem. Phys., 1994, 100, 4229.

69 E. Jiménez, M. Antiñolo, B. Ballesteros, A. Canosa, and J. Albaladejo, First evidence of the dramatic enhancement of the reactivity of methyl formate $\left(\mathrm{HC}(\mathrm{O}) \mathrm{OCH}_{3}\right)$ with $\mathrm{OH}$ at temperatures of the interstellar medium: A gas-phase kinetic study between $22 \mathrm{~K}$ and 64 K, Phys. Chem. Chem. Phys., 2016, 18, 2183.

70 S. D. Le Picard, M. Tizniti, A. Canosa, I. R. Sims, and I. W. M. Smith, The thermodynamics of the elusive $\mathrm{HO}_{3}$ radical, Science, 2010, 328, 1258.

71 M. P. Angappan, G. El Dib, C. Sleiman, A. Tomas, A. Canosa, S. Lakshmipathi, and A. Chakir, An experimental and theoretical study of the kinetics of the reaction between 3Hydroxy-3-Methyl-2-Butanone and OH radicals, Rsc Advances, 2015, 5, 26559.

72 G. El Dib, C. Sleiman, A. Canosa, D. Travers, J. Courbe, T. Sawaya, I. Mokbel, and A. Chakir, First experimental determination of the absolute gas-phase rate coefficient for the reaction of $\mathrm{OH}$ with 4-Hydroxy-2-Butanone $(4 \mathrm{H} 2 \mathrm{~B})$ at $294 \mathrm{~K}$ by vapour pressure measurements of 4H2B, J. Phys. Chem. A, 2013, 117, 117.

73 J. Dojcansky and J. Heinrich, Saturated vapor-pressure of acetonitrile, Chem. Zve., 1974, 28, 157.

74 P. J. Stephens, F. J. Devlin, C. F. Chabalowski, and M. J. Frisch, Ab-Initio calculation of vibrational absorption and circular-dichroism spectra using density-functional forcefields, J. Phys. Chem., 1994, 98, 11623.

75 C. Gonzalez and H. B. Schlegel, An improved algorithm for reaction-path following, J. Chem. Phys., 1989, 90, 2154.

76 L. A. Curtiss, P. C. Redfern, and K. Raghavachari, Gaussian-4 theory, J. Chem. Phys., 2007, 126, 084108. 
77 L. A. Curtiss, P. C. Redfern, and K. Raghavachari, Gn theory, Wiley Interdisc. Rev. - Comp. Molec. Sci., 2011, 1, 810.

78 M. J. Frisch, G. W. Trucks, H. B. Schlegel, G. E. Scuseria, M. A. Robb, J. R. Cheeseman, G. Scalmani, V. Barone, B. Mennucci, G. A. Petersson, H. Nakatsuji, M. Caricato, X. Li, H. P. Hratchian, A. F. Izmaylov, J. Bloino, G. Zheng, J. L. Sonnenberg, M. Hada, M. Ehara, K. Toyota, R. Fukuda, J. Hasegawa, M. Ishida, T. Nakajima, Y. Honda, O. Kitao, H. Nakai, T. Vreven, J. A. Montgomery, J. E. Peralta, F. Ogliaro, M. Bearpark, J. J. Heyd, E. Brothers, K. N. Kudin, V. N. Staroverov, R. Kobayashi, J. Normand, K. Raghavachari, A. Rendell, J. C. Burant, S. S. Iyengar, J. Tomasi, M. Cossi, N. Rega, J. M. Millam, M. Klene, J. E. Knox, J. B. Cross, V. Bakken, C. Adamo, J. Jaramillo, R. Gomperts, R. E. Stratmann, O. Yazyev, A. J. Austin, R. Cammi, C. Pomelli, J. W. Ochterski, R. L. Martin, K. Morokuma, V. G. Zakrzewski, G. A. Voth, P. Salvador, J. J. Dannenberg, S. Dapprich, A. D. Daniels, Ö. Farkas, J. B. Foresman, J. V. Ortiz, J. Cioslowski, and D. J. Fox, Gaussian 09, Revision D.01, Gaussian 09, Revision D. 01, Gaussian, Inc. , Wallingford CT, 2009.

79 M. E. Harding, J. Vazquez, B. Ruscic, A. K. Wilson, J. Gauss, and J. F. Stanton, Highaccuracy extrapolated ab initio thermochemistry. III. Additional improvements and overview, J. Chem. Phys., 2008, 128, 114111.

80 A. Karton, S. Daon, and J. M. L. Martin, W4-11: A high-confidence benchmark dataset for computational thermochemistry derived from first-principles W4 data, Chem. Phys. Lett., 2011, 510, 165.

81 J. M. L. Martin and O. Uzan, Basis set convergence in second-row compounds. The importance of core polarization functions, Chem. Phys. Lett., 1998, 282, 16.

82 T. H. Dunning, Gaussian-Basis Sets for Use in Correlated Molecular Calculations .1. the Atoms Boron Through Neon and Hydrogen, J. Chem. Phys., 1989, 90, 1007.

83 D. E. Woon and T. H. Dunning, Gaussian-basis sets for use in correlated molecular calculations .5. Core-valence basis-sets for boron through neon, J. Chem. Phys., 1995, $103,4572$.

84 H. J. Werner, P. J. Knowles, G. Knizia, F. R. Manby, and M. Schutz, Molpro: a generalpurpose quantum chemistry program package, Wiley Interdisc. Rev. - Comp. Molec. Sci., 2012, 2, 242.

85 M. Kallay and P. R. Surjan, Higher excitations in coupled-cluster theory, J. Chem. Phys., 2001, 115, 2945.

86 G. Knizia, T. B. Adler, and H. J. Werner, Simplified CCSD(T)-F12 methods: Theory and benchmarks, J. Chem. Phys., 2009, 130, 054104. 
87 K. A. Peterson, T. B. Adler, and H. J. Werner, Systematically convergent basis sets for explicitly correlated wavefunctions: The atoms $\mathrm{H}, \mathrm{He}, \mathrm{B}-\mathrm{Ne}$, and Al-Ar, J. Chem. Phys., $2008,128,084102$.

88 J. A. Miller and S. J. Klippenstein, Master equation methods in gas phase chemical kinetics, J. Phys. Chem. A, 2006, 110, 10528.

89 Y. Georgievskii, J. A. Miller, M. P. Burke, and S. J. Klippenstein, Reformulation and solution of the master equation for multiple-well chemical reactions, J. Phys. Chem. A, 2013, 117, 12146.

90 S. J. Klippenstein, Variational optimizations in the Rice-Ramsberger-Kassel-Marcus theory calculations for unimolecular dissociations with no reverse barrier, J. Chem. Phys., 1992, 96, 367.

91 Y. Georgievskii and S. J. Klippenstein, Transition state theory for multichannel addition reactions: Multifaceted dividing surfaces, J. Phys. Chem. A, 2003, 107, 9776.

92 E. Herbst, D. J. Defrees, D. Talbi, F. Pauzat, W. Koch, and A. D. Mclean, Calculations on the rate of the ion molecule reaction between $\mathrm{NH}_{3+}$ and $\mathrm{H}_{2}$, J. Chem. Phys., 1991, 94, 7842 .

93 E. E. Greenwald, S. W. North, Y. Georgievskii, and S. J. Klippenstein, A two transition state model for radical-molecule reactions: A case study of the addition of $\mathrm{OH}$ to $\mathrm{C}_{2} \mathrm{H}_{4}, J$. Phys. Chem. A, 2005, 109, 6031.

94 F. M. Flasar, R. K. Achterberg, B. J. Conrath, P. J. Gierasch, V. G. Kunde, C. A. Nixon, G. L. Bjoraker, D. E. Jennings, P. N. Romani, A. A. Simon-Miller, B. Bezard, A. Coustenis, P. G. J. Irwin, N. A. Teanby, J. Brasunas, J. C. Pearl, M. E. Segura, R. C. Carlson, A. Mamoutkine, P. J. Schinder, A. Barucci, R. Courtin, T. Fouchet, D. Gautier, E. Lellouch, A. Marten, R. Prange, S. Vinatier, D. F. Strobel, S. B. Calcutt, P. L. Read, F. W. Taylor, N. Bowles, R. E. Samuelson, G. S. Orton, L. J. Spilker, T. C. Owen, J. R. Spencer, M. R. Showalter, C. Ferrari, M. M. Abbas, F. Raulin, S. Edgington, P. Ade, and E. H. Wishnow, Titan's atmospheric temperatures, winds, and composition, Science, 2005, 308, 975. 